\title{
The Offense-Defense Balance and The Costs of Anarchy: When Welfare Improves Under Offensive Advantage
}

\author{
R. Daniel Bressler ${ }^{1}$, Robert F. Trager ${ }^{2}$, and Allan Dafoe ${ }^{3}$
}

\begin{abstract}
A large literature has argued that offensive advantage makes states worse off because it can induce a security dilemma, preemption, costly conflict, and arms races. In this paper, we challenge this prevailing wisdom. We argue that state welfare is u-shaped under increasing offensive advantage. We assess the effect of the offense-defense balance by considering a model where two states choose arms levels and decide whether to attack. High defensive advantage is first-best because attacking is difficult and the arms burdens required to deter attacks and maintain peace are low. High offensive advantage is comparatively worse because war is likely, but war tends to be smaller in scale, quicker, and less costly. Intermediate offensive advantage is worst because high arms burdens are required to deter attacks while wars, when they occur, are larger, longer, and more destructive. We discuss historical examples of this phenomenon from the Warring States periods in China and Japan, the Mongol invasions of the Middle East, the Imjin War, the Federalist papers, the Napoleonic Wars, the American Civil War, and the World Wars.

A large literature has argued that offensive advantage makes states worse off because it can induce a security dilemma, preemption, costly conflict, and arms races. We argue instead that state welfare is u-shaped under increasing offensive advantage. We assess the offense-defense balance by considering a model where two states choose arms levels and decide whether to attack. High defensive advantage is first-best because attacking is difficult and the arms burdens required to deter attacks and maintain peace are low. High offensive advantage is comparatively worse because war is likely, but war tends to be smaller in scale, quicker, and less costly. Intermediate offensive advantage is worst because high arms burdens are required to deter attacks while wars, when they occur, are larger, longer, and more destructive. We discuss historical examples of this phenomenon including from the Warring States periods in China and Japan, the Federalist papers, and the World Wars.
\end{abstract}

1. PhD Candidate, Columbia University School of International and Public Affairs. Correspondence to rdb2148@columbia.edu

2. Associate Professor, University of California Los Angeles

3. Associate Professor and Director of the Centre for the Governance of AI, Future of Humanity Institute, University of Oxford 


\section{Introduction}

Does greater offensive advantage necessarily lead to worse outcomes in the anarchical international system? A large body of past literature has suggested that the answer is yes. When offense is advantaged, wars are more likely ${ }^{4}$. Because attacks are more likely to be successful, revisionist states are more likely to attack their rivals. In addition, there are greater incentives for preemption, as states would rather attack than defend in the event of war. Status quo states, who may have little interest in taking their opponent's territory, now have greater reason to fear other states' armies and may end up attacking out of fear. The security dilemma - when one state takes measures to improve its own security, but in the process decreases the security of other states is exacerbated. A state may build up its military to protect itself against surrounding states, but in circumstances in which offense is advantaged, other states are more likely to view this as a threat to their own security. In short, situations in which offense is advantaged are more dangerous and belligerent. Because war is costly and leads to death and destruction, offensive advantage is comparatively dangerous and ruinous relative to sanguine defensive advantage.

In this paper, we challenge this prevailing wisdom. We argue that the relationship between offensive advantage and outcomes in the anarchical international system is more complex. Under certain conditions, we argue that increasing offensive advantage can lead to better outcomes.

We show this by producing a formal model of two single unitary actor states coexisting under anarchy, and by providing a number of historical examples. Our model builds on and extends James Fearon's model from Cooperation, Conflict, and the Costs of Anarchy. ${ }^{5}$ Fearon's goal was to create a baseline model that characterizes the strategic problems facing states interacting in international anarchy, and we found his model useful as a springboard to explore the impact of the offense-defense balance on welfare. Fearon's analysis was focused on determining the conditions under which a peace equilibrium could be supported, and on analyzing the attractiveness of outcomes in peace equilibria. We extend Fearon's analysis to model war equilibria in addition to peace equilibria, and we show how state welfare (defined as the net present value of state payoffs) changes in equilibrium under comparative statics in the offense-defense balance parameter. We further extend Fearon's analysis by exploring equilibria in which states place some value on the present relative to future periods (i.e. they have a discount rate bounded away from zero) and we use constrained optimization methods to solve for a reduced-form solution to the model.

We consider three successively elaborate iterations of this model. In each iteration of the model, we establish propositions that continue to hold in subsequent model iterations. In the first iteration, we consider a single-shot model with exogenous arms

4. Jervis 1978; Van Evera 1998; Gilpin 1983; Glaser and Kaufmann 1998; Hart 1932; Lynn-Jones 1995; Quester 2002.

5. Fearon 2018. 
levels. War, when it occurs, is modeled in reduced-form and the costs of war are exogenous. In the second iteration, we extend the single-shot model into an infinitely repeated dynamic setting where arms are now chosen endogenously, but war continues to be modeled in reduced form and war costs are exogenous. In the third iteration, we extend the dynamic model so that war is modeled as a series of operations and war costs are endogenous.

We show that increasing the offense-defense balance from extreme defensive advantage to extreme offensive advantage causes the game to switch from an equilibrium in which peace is the only outcome to an equilibrium in which war is the only outcome (proposition 1). We show that state welfare is strictly decreasing in offensive advantage in peace equilibria (proposition 2). This is because as offense becomes increasingly advantaged, states must allocate a greater portion of their scarce resources to arms so as to deter the other side from attacking. Because arms cannot be consumed or invested, arms spending reduces welfare. These results are largely in line with past arguments around the offense-defense balance.

When we consider state welfare in war equilibria, however, we find results that depart from arguments made in prior work. We find that increasing offensive advantage increases welfare in war equilibria for two main reasons: (1) Wars tend to be less total ${ }^{6}$ under higher levels of offensive advantage, and (2) Wars tend to be more decisive, shorter, and less costly under higher levels of offensive advantage.

On point (1), we find that once offense is advantaged over the defense, further increases in offensive advantage tend to make wars less total by reducing equilibrium arms spending in war as long as states place some value on the present relative to the future (proposition 3). This is because the returns to arming decrease under increasing offensive advantage. The intuition for this is straightforward: as offense becomes increasingly advantaged, having a marginally larger or better military becomes less important compared to being the attacker in a war. Likewise, if defense is quite advantaged in a war, then a marginally larger or better military is also less important compared to being the defender. Arms provide the greatest return on investment (where returns are measured as an increased probability of winning the war) when there is offense-defense neutrality, i.e. for given force levels, a state has the same probability of winning regardless of whether they are attacking or defending. Therefore, arms investments are the highest and wars are the most total under offense-defense neutrality. As the offense-defense balance shifts away from offense-defense neutrality in either the offensive or defensive direction, arms investments decrease, and wars become less total, which increases the welfare of the states involved.

We demonstrate point (2) by modelling war as a series of operations. We find that under higher levels of offensive advantage, there are fewer expected operations because wars are more likely to end decisively instead of bogging down into a stalemate and

6. By less total, we mean that the war is fought with a lower proportion of the state's resources. In the context of our model, a war is less total when the equilibrium arms spending is lower. 
further operations. Therefore, wars tend to be shorter and less costly under higher levels of offensive advantage. This is consistent with arguments made in a large body of past literature that under higher levels of offensive advantage wars tend to be "shorter," " "quick and decisive,"8 and "relatively quick, bloodless, and decisive." 9

In summary, our analysis suggests that starting from extreme defensive advantage, greater offensive advantage has adverse effects: it creates more conditions under which war occurs, and under peace, it makes states worse off through the higher arms spending required to maintain deterrence. In war equilibria, however, marginally increasing offensive advantage will tend to make states better off for the two reasons stated above. This gives state welfare under offensive advantage a general u-shape (a phenomenon we abbreviate $W U O$ for Welfare is U-shaped under Offensive advantage). Importantly, this suggests that large increases in offensive advantage can cause an absolute increase in state welfare by switching from a costly peace equilibrium burdened by high arms levels to a decisive war equilibrium. (proposition 5).

In short, war is inefficient, but so is a costly peace. A large exogenous increase in offensive advantage due to some change in military technology, for instance, can provide the spark for states to engage in a decisive war that results in state consolidation with no future costs of anarchy because there is no more anarchy. This outcome can be welfare-improving over a continued costly peace. ${ }^{10}$

Historical examples of the phenomena we describe can be drawn from the histories of Japan and China, mentioned briefly here and discussed in more detail in the main body of the paper. Japan endured a bloody period of warring states (the Sengoku Jidai, roughly 1467-1600) in which the country dissolved into hundreds of independent states run by warlords (daimyōs). The prevailing military organization and technology available at the time made it difficult for warlords to conquer and hold large swaths of territory, so the country remained in bloody civil war for over a hundred years. This state of affairs ended only at the end of the 16th century when the three great unifiers of Japan - Oda Nabunaga, Toyotomi Hideyoshi, and ultimately Tokugawa Ieyasu were able to revolutionize military organization and utilize new technologies so that it was possible to conquer and hold large swaths of territory and to ultimately consolidate Japan into a single state, ending the state of anarchy and ushering in the peaceful and prosperous Edo period (1600-1868). Similarly, China endured a bloody period of warring states from 475-221 BC until it was unified by Emperor Qin Shi Huang. Similar to the Japanese Warring States period, the end of this period was marked by increased offensive advantage due to innovations in military organization and

7. Fearon 1995.

8. Glaser and Kaufmann 1998.

9. Jervis 1978.

10. See (Coe 2011) and (Kydd 2015) chapter 7 for analysis of the costly peace and costly deterrence explanations for war as well as (Powell 1993) and (Hwang 2012). (Fearon 2018) footnote 15 shows that Immanuel Kant also identified and described this explanation for war in 1795 (Kant 1983). Our analysis shows that a change in the offense-defense balance towards offensive advantage can be a mechanism by which the equilibrium flips from costly peace to a decisive war, which can be welfare improving. 
technology, in particular, siege technology. At the end of this period, Qin Shi Huang was able to put an end to the warring states period by conquering all of China in a rapid campaign that lasted only 9 years. Historically, China was most prosperous when a single dynasty ruled the country, even though the costs of conquering China were very high in both material and human terms.

Finally, we emphasize that these results should be interpreted with caution. States are best off when defense is highly advantaged and peace can be maintained. Moreover, caution is further required because governments and military leaders in the past have misjudged the offense-defense balance, often in the direction of overestimating the viability of offense. ${ }^{11}$ Much of the death and suffering from war historically has resulted from wars that were expected to be swift and decisive but ended up being years-long attrition contests. These include the 1592 Japanese invasion of Korea, the 1914 Austro-Hungarian invasion of Serbia, the 1937 Japanese invasion of China, the 1941 German invasion of the Soviet Union, the 1950 North Korean invasion of South Korea, and the 1980 Iraqi invasion of Iran. In addition, consolidation through federation is superior to consolidation through war because it achieves the benefit of removing the costs of anarchy while avoiding the cost of war (see conclusion for further discussion). However, our analysis suggests that if consolidation through federation is not possible, then consolidation through war may be welfare improving over a continued costly and risky peace.

\section{Offense-Defense Balance in a Single Stage Model}

We begin by considering a simple single stage version of our model where arming and war costs are exogenous. The players, payoffs, and propositions introduced in this single stage model will remain the same in the two further more elaborate iterations of the model in the following sections. ${ }^{12}$

There are two state actors with resource endowments normalized to 1 . Players are endowed with arms levels $a \in[0,1]$, which are subtracted from their resource endowments. Arms do not provide utility, but are useful in winning a possible war against the other state. Player payoffs are measured in units of their resource endowments, and we make the standard simplifying assumption that player utility is synonymous with their payoffs. Players value international issues, $\gamma \in(0,1)$. In the absence of war, $\gamma$ is divided equally between the states. ${ }^{13}$ Players also place some

11. Hart 1932; Snyder 1984; Van Evera 1984.

12. The payoffs introduced in this section align with the payoffs in Fearon's original model. However, Fearon's model was focused on determining conditions under which the peaceful equilibrium could be maintained by arming up enough to deter an opponent from attacking. We begin to extend Fearon's model in this section by analyzing war equilibria, both (1) when one player attacks and the other defends, and (2) when both players simultaneously attack each other.

13. In this simplified iteration of the model, we make the assumption that $\gamma$ is divided evenly in peace equilibria, but in following model iterations, we will discuss the role of bargaining. 
value on ruling the other state's territory in the event that they win the war, $\mu \in[0,1]$.

Players simultaneously choose whether to attack or not attack. There is only peace when neither side attacks. Although actions take place in a single stage, payoffs are assumed to last in perpetuity ${ }^{14}$ and are discounted by the factor $\delta \in[0,1)$. War is treated as a costly lottery where the loser is eliminated and gets a payoff of 0 henceforth. The winner gets full control of issues $\gamma$ and the other sides' endowment $\mu$ henceforth. The winner continues to receive their resource endowment without further need for arms spending because the other side has been eliminated in the war. The winner must also pay the costs of war $c \geq 0$. We assume that these costs are paid in perpetuity for convenience. ${ }^{15}$ We make the simplifying assumption that the two states have identical preferences, resources, and arms levels.

In summary, the benefit from winning a war ${ }^{16}$ is given by:

$$
\frac{\gamma-c+\delta(1+\mu)}{1-\delta}=\frac{w}{1-\delta}
$$

We simplify the notation by defining $w=\gamma-c+\delta(1+\mu)$ as the single-period benefit of winning the war, which is then converted into a perpetuity by dividing by $1-\delta$.

The probability of victory for state $\mathrm{i}$ in a war with state $\mathrm{j}$ is determined by the contest success function (CSF) $p^{i}\left(a_{i}, a_{j} ; m\right) .{ }^{17}$ The probability of victory for state $\mathrm{i}$ attacking state $\mathrm{j}$ is given by the $\operatorname{CSF} p_{o}^{i}\left(a_{i}, a_{j} ; m\right)$, the probability of victory for state $\mathrm{i}$ defending against state $\mathrm{j}$ is determined by the $\operatorname{CSF} p_{d}^{i}\left(a_{i}, a_{j} ; m\right)$, and the probability of victory for state $\mathrm{i}$ when state $\mathrm{i}$ and state $\mathrm{j}$ simultaneously attack is determined by the CSF $p_{s}^{i}\left(a_{i}, a_{j} ; m\right) . m \geq 0$ is the offense-defense parameter. A larger $\mathrm{m}$ implies greater offensive advantage, i.e. for a fixed level of arms levels, the greater the probability that the attacker has of winning the war. A formal treatment of CSFs and their relationship to the offense-defense balance is given in the appendix. ${ }^{18}$

14. We make this assumption so that we can use the payoffs from this section in all subsequent sections when the model is extended into an infinitely repeated setting.

15. Following Fearon, although the costs of war can theoretically enter the model in a variety of ways, this ensures that the cost term is relevant when we consider the case when $\delta \rightarrow 1$.

16. Note that this is the payoff from the period after the war onward.

17. In this single-shot model, arms levels are exogenous and identical between the two states, so the CSF is determined only by the offense-defense balance. When we embed this single-shot model in a dynamic setting with endogenous arms levels in the following section, the distinction between $a_{i}$ and $a_{j}$ will become relevant.

18. For brevity, we will sometimes drop the state superscript and all or some of the variables of the function. We represent the CSF simply as $p_{o}, p_{d}$ or $p_{s}$ when we want to emphasize whether a state is attacking, defending, or if there is simultaneous attack. We represent the CSF simply as $p(m)$ when we want to present a general CSF without specifying whether the state is attacking or defending, but emphasizing that the CSF is a function of the offense-defense balance. Regardless of the notation, the CSF always represents some state's probability of victory in a war with another state, is defined either in the context of an attack, a defense, or a simultaneous attack, and is always a function of the states' arms levels and the offense-defense balance. 
The general expected payoff from war (not specifying whether the player is attacking, being attacked, or if there is simultaneous attack) is given by:

$$
E U(\text { War })=1-a+p(m) * \frac{w}{1-\delta}
$$

The expected payoff from peace is:

$$
E U(\text { Peace })=\frac{1-a+\gamma / 2}{1-\delta}
$$

Under peace, we assume that both players continue to spend $a$ on arms in perpetuity. A summary of this single shot model in strategic form is shown in figure 1

FIGURE 1. The Single Stage Model in Strategic Form

No Attack \begin{tabular}{|l|ll|} 
Attack & $1-a+p_{s} \frac{w}{1-\delta}$ & $1-a+p_{d} \frac{w}{1-\delta}$ \\
\cline { 2 - 4 } & $1-a+p_{s} \frac{w}{1-\delta}$ & $1-a+p_{o} \frac{w}{1-\delta}$ \\
\hline $1-a+p_{d} \frac{w}{1-\delta}$ & $\frac{w}{1-\delta}$ & $\frac{1-a+\frac{\gamma}{2}}{1-\delta}$ \\
\hline
\end{tabular}

\section{Defining The Offense-Defense Balance Parameter}

So what exactly do we mean by the offense-defense balance in this model? Past literature has used a variety of definitions for the offense defense balance including the ease of territorial conquest, ${ }^{19}$ the characteristics of armaments that favor either attackers or defenders, ${ }^{20}$ the relative resources needed by the offense in order to overcome the defense, ${ }^{21}$ and the ratio of the cost of the forces that the attacker requires to take territory to the cost of defender's forces. ${ }^{22}$ There are also differences

22. Glaser and Kaufmann 1998; Lynn-Jones 1995. 
in the factors that past scholars have argued affect the offense-defense balance. Is the offense-defense balance only determined by military technology, or is it also determined by doctrine and geographic factors? Is the offense-defense balance a system-wide variable that applies to any conflict that takes place at a certain point in time, or does it vary at a given point in time depending on situation-specific factors? Does the offense-defense balance apply to specific military campaigns, to whole wars, or to both? Past analyses have answered these questions in different ways. ${ }^{23}$

In our model, the offense-defense balance is defined in the context of a CSF that determines the probability that one side wins a contest versus another side. ${ }^{24}$ Because we are working with a dyadic model, we are considering a dyad-specific offense-defense balance, and we do not consider potential balancing or bandwagoning effects.The CSF is a function of each side's arms levels and the offense-defense balance. The offense-defense balance is a variable that represents all of the factors outside of arms levels that increase an attacker's chance of success relative to the defender or vice versa.

This implies that we take a broad interpretation of the offense-defense balance: military technology, doctrine, geography, nationalism, psychology, and other factors can all in principle affect the offense-defense balance parameter, provided they increase or decrease an attacker's chance of success against a defender for given arms levels.

To illustrate: the development of military technology ${ }^{25}$ such as better siege weapons can shift the offense-defense balance in favor of the offense because they make fortifications a less effective means of protecting territory. ${ }^{26}$ For a given set of technologies, changes in military doctrine can favor either the offense or defense. For instance, Nazi Germany's organization of independent Panzer divisions that could race ahead of the infantry to encircle enemies in large kesselschlacht (cauldron battles, or battles of encirclement) shifted the balance in favor of attackers relative to doctrines that placed tanks in infantry divisions so that they moved at the speed of the infantry. Defense-in-depth tactics - where defense is constructed in multiple layers that all must be breached instead of a single layer - such as those employed by the Germans in the

23. (Levy 1984) primarily considered military technologies and doctrine. (Mearsheimer 2001) identified the "stopping power of water" as a critical geographic factor consistent across time that favors defenders that have to be invaded by sea, although he did not define this concept explicitly within the context of offense-defense balance. (Glaser and Kaufmann 1998) argued that their definition of offense-defense balance should apply to whole wars, and not specific battles. (Biddle 2001) argued that offense-defense balance applies at the operational level and the best defensive strategies typically involve "defense in depth" in which the defender may give ground to the attacker, but have forces in reserve that can counterattack. (Lieber 2000) argues that focusing the offense-defense balance concept on technology is more useful than considering a broader range of factors.

24. We use the offense-defense balance parameter in the same way as (Fearon 2018). See equations (5), 6), and (7) and subsequent discussion below.

25. A good deal of recent literature has explored how advances in cyberwarfare affect the offense-defense balance, including (Garfinkel and Dafoe 2019; Gartzke and Lindsay 2015; Slayton 2017; Lieber 2014).

26. See our later discussion of the Japanese and Chinese Warring States Periods for more detail on the effect of siege weapons. 
1917 Second Battle of the Aisne and by the Soviets in the 1943 Battle of Kursk, can shift the balance in favor of defenders. ${ }^{27}$

Geographic factors that make it harder to project force when invading, such as large bodies of water, tend to shift the balance in favor of defenders. ${ }^{28}$ Nationalism can provide defensive advantage when armies feel that they are protecting their homeland against invaders, e.g. for the French in the 1792 campaigns of the War of the First Coalition as captured in the song "Chant de Guerre pour l'Armée du Rhin," which has since become the French National anthem.

Separate from nationalism, psychological factors can also affect the offense-defense balance. The phenomenon of loss aversion predicted by prospect theory may cause defenders to fight harder to defend ground that they believe is theirs relative to attackers that believe that they are capturing new territory. ${ }^{29}$ When defenders believe that they will be massacred by attackers, they are more likely to fight to the death instead of surrendering, shifting the balance towards the defense. ${ }^{30}$ Historical examples of this include Nazi Germany's Commissar Order to summarily execute Political Commissars when they invaded the Soviet Union in 1941 and Hulagu Khan's threats against the Mamluk Sultanate that strengthened the resolve of the Mamluks in their victory over the Mongols at Ain Jalut in 1260. ${ }^{31}$

27. These examples bring up the important historical consideration that one side may figure out how to optimally employ technology in their doctrine before the other side, as discussed in (Fearon 1995). For instance, the Germans in the 1940 Battle of France placed nearly all of their armor in 10 independent Panzer divisions, such as Erwin Rommel's famed "Ghost Division," that could take advantage of the tank's speed in attack whereas the French integrated more of their tanks in with their infantry units (Zaloga 2014). For this reason, we might expect that a German attack on France would favor the offense more than a French attack on Germany. Our model makes the simplifying assumption that both sides are symmetric in their resources, preferences, and they share a common offense-defense balance. One could relax this assumption so that there is a different offense-defense balance depending on who is in attack. In this case, the mechanisms identified in this paper that contribute towards WUO - (1) Higher arming required to deter adversaries when they enjoy higher offensive advantages (2) Lower returns to arms under increasing offensive advantage and (3) More decisive and less costly wars - would still hold, although this would significantly complicate the analysis.

28. See (Mearsheimer 2001) for a discussion of the stopping power of water.

29. See (Levy 1997) and (Levy 2000) for discussion.

30. Some of these factors affecting the offense-defense balance may arise endogenously as a strategic response. However, our model treats the offense-defense balance as exogenous for analytical tractability and to understand how outcomes change when factors external to the model cause the offense-defense balance to change. See the conclusion for a discussion of how the balance can change endogenously and suggestions for future work.

31. In 1260, Hulagu Khan sent a letter to Sultan Qutuz of the Mamluk Sultanate reading: "Resist and you will suffer the most terrible catastrophes. We will shatter your mosques and reveal the weakness of your God, and then we will kill your children and your old men together" (Tschanz 2007). Similar threats were commonly used by the Mongols as part of a psychological warfare strategy to coerce enemies into capitulating without a fight. To make these threats credible, they would spare states that gave into the demands and they would crush those that opposed them with extreme brutality. Just two years earlier, Hulagu Khan had sent a similar letter to the Abbasid Caliphate. When they defied him, he destroyed Baghdad in 1258 in one of the most brutal atrocities in history; estimates of the number of deaths range from the hundreds of thousands to the millions (Iskandar et al. 2001; Wink 1991). Such tools of psychological 
The factors relevant to understanding the offense-defense balance varies significantly across dyads and across time. For example, geographic factors can be critical. Over centuries, the offense-defense balance in the France-Germany dyad favored the offense more-so than the Britain-France dyad, due to the English Channel and the stopping power of water. In the Napoleonic Wars, Napoleon was able to facilitate swift movement of his armies deep in enemy territory by having them live off of the land instead of burdening them with large supply columns. When fighting Austria and Prussia in agriculturally-dense central Europe, this strategy worked well. His ability to move his armies swiftly allowed him to conduct rapid battles of encirclement, ${ }^{32}$ and allowed him to quickly position his army near his enemy's capitals to force them into decisive battles. ${ }^{33}$ Russia, in contrast, was poorer and less agriculturally-dense. Therefore, Napoleon could not employ the living off of the land strategy there. In his 1812 invasion of Russia, Napoleon had to provide for a vast network of supply columns that slowed his movement, making it more difficult to force the Russians into a single decisive battle. ${ }^{34}$ Together, these factors imply that the France-Russia dyad during the Napoleonic wars was more defense-dominant than the France-Austria or France-Prussia dyad.

In addition, it is important to clarify what we mean by "attacker," and "defender." In our model, the attacker is the side that strikes first in a war. The examples given at the end of the introduction all capture what we mean by attacker: Japan in their 1592 invasion of Korea, Austria-Hungary in their 1914 invasion of Serbia, Germany in their 1941 invasion of the Soviet Union, North Korea in their 1950 invasion of South Korea, and Iraq in their 1980 invasion of Iran. The attacker in our model is not necessarily the country that declares war first; it is the country that attacks first. For instance, in the War of the Fourth Coalition in 1806, Prussia declared War on France first, but under our definition, France was the attacker and Prussia was the defender because Napoleon quickly responded to Prussia's declaration of war by invading Prussian territory. Between 1939-1941, Nazi Germany was a prolific attacker under our definition, launching large-scale invasions of Poland, Denmark, Norway, the Netherlands, France, Yugoslavia, Greece, and the Soviet Union. A historical example

warfare either amplify the offense-defense balance towards more extreme offensive advantage or more extreme defensive advantage. When they work, they cause extreme offensive advantage because the defender gives up without a fight. When the defender does not capitulate, however, they contribute towards stronger defensive advantage because the defender either wins or faces certain death. In the case of the Mamluk Sultanate, Hulagu Khan's threats backfired and ended up favoring the defense: before the battle, Sultan Qutuz gave a speech to his troops stating that there was no alternative to winning except a horrible death for themselves and their families, as the Mongols had made clear in their threats and with their actions in Baghdad. The speech was effective in inspiring the men to fight exceptionally hard in close-quarter fighting at the Battle of Ain Jalut, annihilating the Mongol force in a decisive victory that some observers claimed saved Islam from the Mongol hordes (Amitai-Preiss 2004)

32. Such as at Ulm (1805)

33. Such as Austerlitz (1805), Jena-Auerstedt (1806), and Wagram (1809).

34. In addition, the vast amount of territory between the Neman River and Moscow allowed the Russians to trade space for time much more easily than Austria and Prussia. 
that captures what we mean by simultaneous attack are the attacks carried out by Germany (the Shlieffen Plan) and France (Plan XVII) in 1914. These attacks were executed at roughly the same time to initiate the Western Front theater of operations in World War I. ${ }^{35}$

In the first two iterations of our model, we consider the offense-defense balance at the strategic level (i.e. the level of the outcome of the war). In the third iteration of our model, we consider war as a series of operations, and the offense-defense balance applies at the operational level. We show in that section that offensive advantage at the operational level also implies offensive advantage at the strategic level.

\section{Results from the Single Stage Model}

Whether a peace equilibrium can be supported in the single stage model shown in Figure 1 depends on the best response to a non-attacking defender. We define this condition as the static war constraint. ${ }^{36}$

$$
\frac{1-a+\gamma / 2}{(1-\delta)} \geq 1-a+p_{o}(m) \frac{w}{(1-\delta)}
$$

Depending on the offense-defense balance and the static war constraint, the game can take one of four different structures. These game structures determine three different strategic contexts that have been much discussed in the international relations literature, Offensive War (scenario 1), Security Dilemma (scenario 3), and Stable Deterrence (scenario 4), as well as an outcome that is less discussed in international relations: Rope-A-Dope (scenario 2). Figure 2 shows these four outcomes with their pure strategy Nash equilibria represented with the label N.E. Delineation into columns indicates whether a predatory attack is attractive or not, i.e. whether the static war constraint is satisfied. ${ }^{38}$ Delineation into rows determines whether offense or defense is advantaged.

35. Germany launched a large-scale attack through Belgium into Northern France beginning on August 5, 1914 and France launched a large-scale attack into Alsace-Lorraine under their Plan XVII beginning on August 7, 1914. Both sides believed that the balance favored the offense, and they thus both believed it was a best-response to attack, resulting in a simultaneous attack equilibrium. Ultimately, the German attack was more successful (which fits with our coin flip simultaneous attack CSF, see equation 7 below for more detail), as the French attack was pushed back immediately at the Battle of Mulhouse while the German attack nearly reached Paris before being pushed back at the First Battle of the Marne. From there, the Germans subsequently retreated and dug into defensible positions along the Aisne river, initiating the Race to the Sea and setting off the Western Front lines that would remain fairly static for most of the war.

36. We call this the static war constraint to differentiate it from the dynamic war constraint where arms levels are chosen in a multi-stage process in the next section. If the static war constraint holds, then remaining at peace is more attractive than a predatory attack, ${ }^{37}$ and a peace equilibrium can be supported. If the war constraint does not hold, then a predatory attack is more attractive than remaining at peace. Formally, the static war constraint holds when:

38. For simplicity, we assume that "the tie goes to peace." If the war constraint holds with equality, then we assume that (no attack) is the only best response to (no attack), i.e. a predatory attack is not attractive. 
FIGURE 2. The Four Scenarios of the Single Stage Game

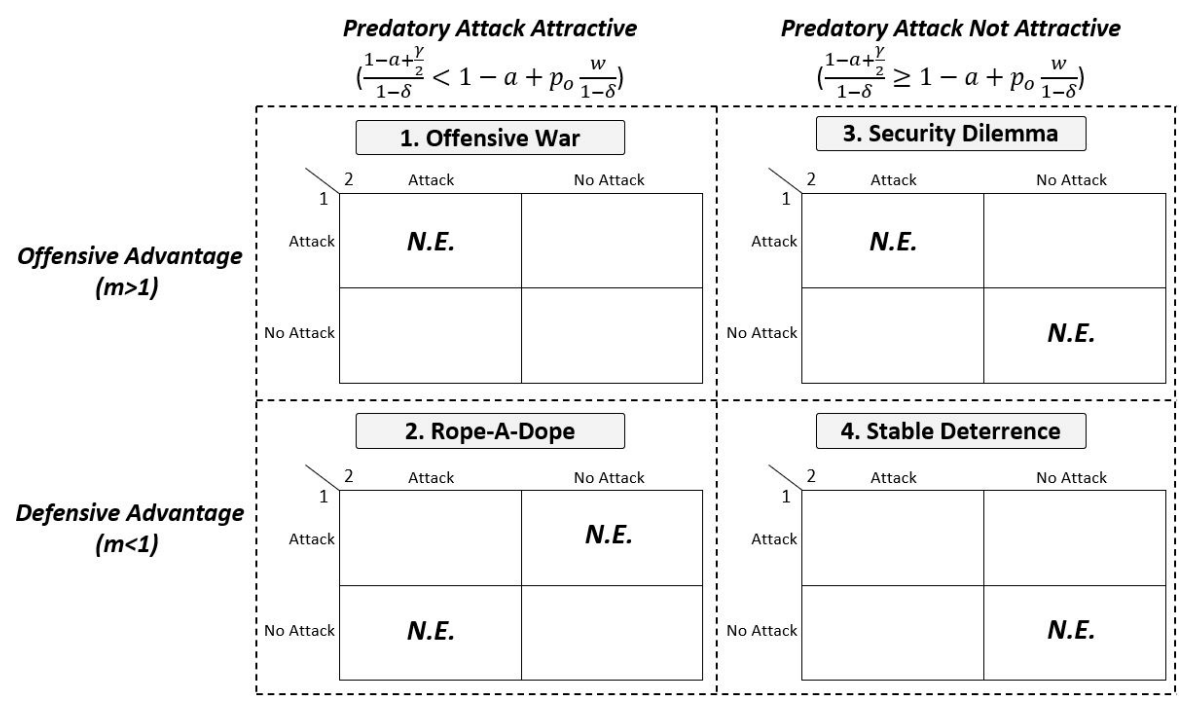

When offense is advantaged (top row), states do not want to get stuck defending in a war. Therefore, a state's best response is to attack when they expect the other side to attack. There is always an equilibrium where both sides simultaneously attack regardless of whether the static war constraint is satisfied.

When defense is advantaged (bottom row), states prefer to being the defender in the event of war. Therefore, when states expect the other side to attack, their best response it to defend. There is never a pure strategy equilibrium where states simultaneously attack regardless of whether the static war constraint is satisfied.

When the war constraint is not satisfied, (left column) all pure strategy Nash equilibria involve war because the best response to a non-attacking state is to attack.

When the war constraint is satisfied (right column), then at least one of the pure strategy Nash equilibria involves peace because the best response to a non-attacking state is no attack.

Scenario 1 - when offense is advantaged and the static war constraint is not satisfied - yields Offensive War. In this scenario, countries seek hegemony through conquest because attack is the dominant strategy for both players and war is the only equilibrium outcome. A historical example that captures this equilibrium is the simultaneous attack by both France and Germany to initiate the Western Front theater of operations in World War I described earlier. Although they were mistaken, both sides believed that the balance favored the offense, and they thus both believed it was a best-response to attack, resulting in a simultaneous attack equilibrium.

Scenario 3 - when offense is advantaged and war is relatively less attractive - yields 
dynamics similar to the Security Dilemma. In this scenario, war is not preferable for either party and we might expect states to be able to cooperate to avoid war. However, if the sides believes that the other will attack, the game can end up in the Pareto dominated pure strategy Nash equilibrium of simultaneous attack because a country's best response to an attacker is to also attack to avoid being the disadvantaged defender in war. ${ }^{39}$ This scenario is similar to the "doubly dangerous" scenario described by Jervis (1978) in his discussion of the Security Dilemma. ${ }^{40}$ This game has the structure of a stag hunt: a coordination game with multiple pure strategy Nash equilibria of simultaneous attack and peace.

Scenario 4 - when defense is advantaged and war is relatively less attractive results in Stable Deterrence. No attack is the dominant strategy for both countries. This is the only scenario in which war is not an equilibrium. Even though attacking is an option available to states and there is no global government to enforce contracts between them, it is a never best response because war is relatively unattractive compared to peace ( $w$ is sufficiently low), and defensive advantage implies that states are better off letting a state attack them if they believe another state is planning to attack.

Scenario 2 - when defense is advantaged, but war is relatively more attractive yields hypotheses that are less discussed in international relations. We call scenario 2 the "Rope-a-Dope" scenario. The best outcome for a state in this scenario is to be attacked by their opponent so that they can leverage defensive advantage and have the best chance of winning the war. A state's best response to a non-attacking opponent is to attack despite defensive advantage due to the unattractiveness of peace relative to a decisive war. This gives the game an anti-coordination structure that resembles the game of chicken. ${ }^{41}$ This requires a predatory attack to be preferred to peace even though the offense-defense balance favors defenders, which implies that the benefit from winning a war is quite high (high $w$ ). Historically, this logic seems to undergird

39. We get this result even though this is a game of complete information, and therefore there is no uncertainty about players' types and their intentions, although the model could be extended to include incomplete information.

40. Jervis 1978 .

41. This scenario is named after the strategy employed by Muhammad Ali in his famed "Rumble in the Jungle" fight with George Foreman in 1974. Ali's strategy was to allow the hard-punching Foreman to take the offensive. Ali was good defensively and he could use the ropes of the boxing ring to aid in absorbing Foreman's blows. This had the effect of causing Foreman to tire, allowing Ali to counterattack late in the fight and to knock out Foreman. The strategy is called "Rope-A-Dope" because Ali appeared to be a "dope" on the ropes who was taking a beating from Foreman, but in actuality he was pursuing a defensive strategy to let Foreman tire himself out on the offensive so that he could counterattack later and ultimately win the fight (Erenberg 2019). 
decisionmaking on multiple occasions when defense was advantaged in wartime. ${ }^{4243}$

In addition to the four scenarios shown in Figure 2, there is another possible scenario: the cost of a war may be so high that peace is preferable to a predatory attack that succeeds with $100 \%$ certainty. In this case, attacking is a never best response irrespective of the offense-defense balance. We call this the Pyrrhic Victory Condition.

Definition 1: Pyrrhic Victory Condition: If war costs are sufficiently high such that peace is preferred to a predatory attack that succeeds with $100 \%$ certainty, then attacking is a never best response and the Pyrrhic Victory condition holds.

Formally, the Pyrrhic victory condition holds in the single stage model when the following inequality holds:

42. On the Western Front in World War I. In 1915, the Germans withstood a series of Entente offensives against their entrenched positions that all resulted in little ground taken despite local Entente force superiority and much higher casualties for the attackers relative to the defenders. These include winter offensives at the First Battle of Champagne and the First Battle of Artois (December 1914-January 1915), a spring offensive at the Second Battle of Artois (May-June 1915), and Autumn offensives at the Third Battle of Artois and the Second Battle of Champagne (September-November 1915). Because of their futility, historian A.J.P. Taylor describes the Entente offensives of 1915 as having "no meaning except as names on a war memorial" (Taylor 1963). These results convinced German General Staff Chief Erich von Falkenhayn that the key to victory on the Western Front was to goad the French into attacking German defensive positions so that German artillery and machine guns could cut down attacking troops in open ground and "bleed white" the French army. This was the strategy that informed the planning for the 1916 Battle of Verdun. Falkenhahyn's experience in the Second Battle of Champagne in particular informed his planning for Verdun. In this battle, the French failed to break through German defenses despite three to one local superiority in manpower and artillery. French attacks on German defensive positions led to enormous casualties for the French relative to the Germans, which Falkenhayn believed to be three to one, though subsequent scholarship has estimated the ratios at between two to one and three to two (Foley 2005; Sondhaus 2011). Falkenhayn planned a limited offensive to threaten the culturally significant city of Verdun while securing important high-ground around the city. From there, the German artillery could decimate French counterattacks. Falkenhayn expected that five Frenchmen would be taken out of action for every two Germans, (Watson 2014) which would force the French into a manpower shortage that would knock them out of the war. In reality, while the initial German advance was successful, many of the advancing German troops overran the limited objectives set by Falkenhayn to weaker positions, and they failed to capture some of the important strategic high ground, which made them vulnerable to French artillery barrages. The result was an almost year-long stalemate with a similar numbers of casualties on both sides that numbered over 700,000 men (Philpott 2015).

43. Arguably a similar logic undergirded some British thinking around Operation Sea Lion, the planned German invasion of the United Kingdom in 1940. Winston Churchill knew that invasions by sea tend to especially favor defenders - a lesson he learned from his role in planning the failed Gallipoli landings in 1915 (Carlyon 2002; Moorehead 2015) - an advantage further magnified by the UK's especially powerful Royal Navy. Although the Germans called off the planned invasion, Churchill said of the plan: "Had the Germans possessed in 1940 well trained [and equipped] amphibious forces their task would still have been a forlorn hope in the face of our sea and air power... there were indeed some who ... for the sake of the effect the total defeat of his expedition would have on the general war, were quite content to see him try" (Churchill 1987) 


$$
\frac{1-a+\gamma / 2}{1-\delta}>1-a+\frac{\gamma-c+\delta(1+\mu)}{1-\delta}
$$

This simplifies to:

$$
c>\frac{\gamma}{2}+\delta(\mu+a)
$$

If the Pyrrhic Victory condition holds, then (no attack, no attack) is the only Nash equilibrium irrespective of the offense-defense balance. ${ }^{44}$ In practice, the Pyrrhic victory condition could result from the introduction of nuclear weapons or devastating conventional weapons that impose high costs on the victor. ${ }^{45}$ This illustrates how factors that increase the cost of war, such as nuclear weapons, can deter war separately from their affect on the offense-defense balance. ${ }^{46}$

With the exception of the offense-defense balance, all of the variables affect the game structure by affecting the attractiveness of war relative to peace, which tightens or loosens the static war constraint. Increasing greed for the other side's territory (higher $\mu$ ) and decreasing the costs of war (lower $c$ ) make war more attractive (higher $w$ ), which tightens the static war constraint. Higher arms levels (higher $a$ ) also make war more attractive because arms are only needed in the single period of the decisive war and not needed after hegemony has been obtained whereas in peace, arms must be spent in perpetuity.

The effect of the offense-defense balance is more complicated than any other variable in the model because it effects the game both continuously and categorically, whereas the other variables (e.g. $\mu, c$, and $a$ ) affect the game only continuously. The offense-defense balance affects outcomes continuously because it changes the attractiveness of war for attackers relative to defenders. The more offense is advantaged (higher $m$ ), the higher the expected payoff from war for attackers ${ }^{47}$ and the lower the expected payoff from war for defenders ${ }^{48}$ regardless of whether $m<1$ or $m>1$. The result is that higher offensive advantage makes a predatory attack more attractive and tends the game towards war equilibria and away from peace equilibria, similar to more

44. If defense is advantaged and the Pyrrhic Victory condition holds, then the game structure is Stable Deterrence. However, there are Stable Deterrence scenarios where the Pyrrhic Victory condition does not hold: i.e. scenarios where a predatory attack is unattractive given the current probability of victory, but a predatory would be attractive if victory could be guaranteed.

45. Assuming that two states have nuclear weapons and possess a credible second-strike capability. Nuclear weapons could contribute towards extreme offensive advantage if states can quickly destroy all of the enemy's forces through a preemptive counter-force strike. If both states possess a credible second-strike deterrent, however, then there is mutually assured destruction and such an attack is not possible without receiving a retaliatory strike that imposes enormous costs on the attacker and leaves both sides' forces depleted.

46. Although the use of nuclear weapons in the event of war would have to be credible for this to hold.

47. Formally $\frac{\partial p_{o} * \frac{w}{1-\delta}}{\partial m_{w}}>0$

48. Formally $\frac{\partial p_{d}^{*} \frac{w}{1-\delta}}{\partial m}<0$ 
greed for the other side's territory (higher $\mu$ ), lower costs of war (lower $c$ ), and higher arms levels (higher $a$ ).

The difference between defensive advantage $(m<1)$ and offensive advantage $(m>1)$ changes the structure of the game categorically from scenario 2 (Rope-ADope) to scenario 1 (Offensive War) when a predatory attack is attractive. Thus, as long as a predatory attack was already attractive before the discrete jump, switching from defensive advantage to offensive advantage is arguably less consequential because the game switches from one war pure strategy equilibrium (where one side attacks and one side defends in scenario 2) to another war pure strategy equilibrium (simultaneous attack in scenario 1). However, if a predatory attack is unattractive both before and after the discrete jump from defensive advantage to offensive advantage, then the structure of the game switches from scenario 4 (Stable Deterrence) to scenario 3 (Security Dilemma).

In short, the net effect of increased offensive advantage in this one-shot model with exogenous arms, in both its continuous and discrete effects, is to tend the game structure away from peace equilibria and towards war equilibria. Insofar as war is costly and leads to death and destruction, the sanguine defense-advantaged world is preferable to the offense-advantaged world as past scholars have argued. We summarize this result in the following proposition:

Proposition 1: In the one-shot model with exogenous arms levels and with sufficiently low war cost (c) such that that the Pyrrhic Victory condition does not hold, for sufficient defensive advantage (sufficiently low $m$ ), peace is the only equilibrium outcome; for sufficient offensive advantage (sufficiently high $\mathrm{m}$ ), war is the only equilibrium.

This result is consistent with past arguments on the offense-defense balance: greater offensive advantage tends to lead to a less-preferred world because it tends to lead to a greater prevalence of war. However, the analysis in this section is necessarily limited because arms are exogenous. In reality, states choose the proportion of their resources to invest in arms in response to their strategic environment. In the next section, we embed this one-shot model in a dynamic setting with endogenous arms choices.

\section{A Dynamic Model with Endogenous Arming and Exogenous War Costs}

In this section, we embed the single stage model from the previous section in a dynamic model in which states choose the fraction of their resources to devote to arms spending. The players, their payoffs, and their resource endowment remain the same as in the previous section, but we now add a stage that occurs immediately before 
the stage from the previous section in which both players simultaneously choose how much of their resource endowment to consume versus how much to spend on arms. After this first stage, both players observe each side's arms levels and then the game continues into a second stage that is identical to the one stage game described in the previous section.

In addition, these two stages are now infinitely repeated. As before, if the game results in any of the war equilibria, there is a decisive war in which one side wins and gets the winning payoff in perpetuity while the losing side is eliminated and gets a payoff of 0 henceforth. If the game results in peace, however, the game continues to the next time period where these two stages are repeated again. Following Fearon, we will assume that when peace is an equilibrium, players will engage in an unspecified bargaining process over international issues $\gamma<1$ where bargaining power is a function of arms levels and $\gamma$ is allocated according to the bargaining $\operatorname{CSF} q_{i}\left(a_{i}, a_{j}\right)$, which meets the conditions specified in Fearon 2018. When war is an equilibrium, the winning state will gain full control of $\gamma$.

A summary of this dynamic model with endogenous arms levels and exogenous war costs is shown in Figure 3 . 


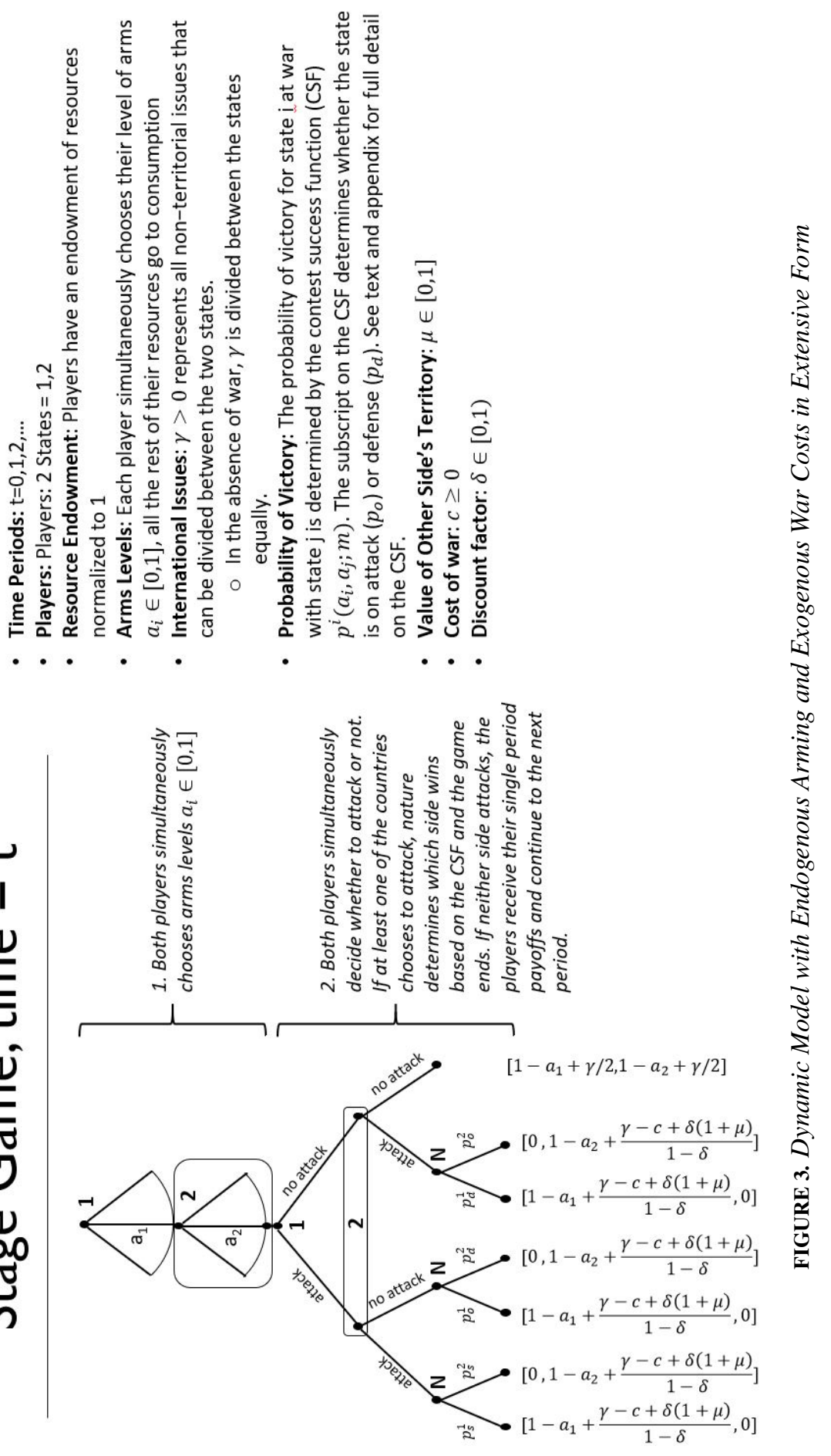


In his 2018 model, Fearon argued that the arms spending required to maintain peace through deterrence represents a theoretically defensible measure for the costs of anarchy in peace: military spending is wasteful since it cannot be consumed to increase welfare. In our model, we generalize Fearon's costs of anarchy concept to cover outcomes in both peace and war equilibria. We define welfare as the present value (PV) of states' payoffs in some outcome. We define the costs of anarchy as the difference between the PV of a state's payoffs in that outcome and the PV of a state's payoffs in the maximum cooperation outcome in which states exist in a state of perpetual peace with no arms spending and evenly split international issues. The lower a state's welfare, the higher the costs of anarchy. ${ }^{49}$ This extended model is now able to consider the costs of anarchy under both war and peace scenarios. We retain the assumption from the previous section that the two states have identical preferences and their payoffs are measured in units of their identical resource endowments. Therefore, we can make interstate comparisons of welfare. We will throughout this analysis consider total welfare, which is the aggregate of the PV of both states' payoffs.

As in the one-shot game, a peace equilibrium can be supported if each sides' arms levels are high enough such that they deter the other side from engaging in a predatory attack. The difference here is that arms are now an endogenous choice. In order for a peaceful equilibrium to be feasible, there must exist some $\hat{a} \in[0,1]$ that meets the following dynamic war constraint condition:

$$
\frac{1-\hat{a}+\gamma / 2}{(1-\delta)} \geq \max _{a} 1-a+p_{o}(a, \hat{a} ; m) \frac{\gamma-c+\delta(1+\mu)}{(1-\delta)}
$$

The LHS of the dynamic war constraint represents a state's welfare when it chooses arms level $\hat{a}$ and neither side attacks in every period. The RHS of the war constraint represents the welfare of a state that makes a predatory attack on another state that chooses arms level $\hat{a}$, and where the attacking state's arms levels are chosen to maximize their welfare. As long as there exists some $\hat{a}$ that satisfies this dynamic war constraint, then a subgame perfect Nash equilibrium (SPNE) with perpetual peace can be supported. This is because if a state i chooses arms level $a_{i}=\hat{a}$, then an opponent $\mathrm{j}$ may consider arming up to attack, but that opponent could achieve higher expected utility by also spending $a_{j}=\hat{a}$ and not attacking. Following Fearon, we focus on the Pareto Optimal (undominated) SPNE of the game. When the dynamic war constraint can be satisfied, the Pareto Optimal SPNE is a peaceful equilibrium in which states choose the $a^{*}$ that solves the war constraint with equality in every period. This $a^{*}$ is the arms level that allows states to maximize their consumption by minimizing their arms burden while maintaining deterrence against a predatory attack. As we showed in the previous section, satisfying the war constraint is a necessary but not sufficient

49. Because the factors determining state payoffs are given exogenously with the exception of arms spending, the PV of a state's payoffs in the maximum cooperation outcome in which there is no arms spending outcome is given exogenously. Therefore, higher welfare is synonymous with lower costs of anarchy. We generally measure outcomes in terms of welfare in this paper. 
condition for peace. When offense is advantaged $(m>1)$ and the war constraint is satisfied (i.e. scenario 3: Security Dilemma), there are always equilibria where both players attack because they expect the other side to attack. However, simultaneous attack in scenario 3 is Pareto dominated by peace. When there are multiple SPNE, the focus of the welfare analysis in this section is on the Pareto Optimal SPNE. When defense is advantaged $(m<1)$ and the war constraint is satisfied (i.e. scenario 4: Stable Deterrence), then perpetual peace is the only SPNE outcome. ${ }^{50}$

Following Fearon, we make the assumption that the Nash Equilibrium arms levels $\left(A_{N E}\right)$ are larger than $\mathrm{a}^{*}$ when peace is an equilibrium. Functionally, this allows us to determine a single Pareto Optimal SPNE value for arms levels and to avoid equilibria with random arms levels and a positive chance of attack that were described in (Jackson 2009). ${ }^{51}$

If there does not exist some $\hat{a} \in[0,1]$ that satisfies the dynamic war constraint, this implies that there is not a peaceful SPNE because an opponent's best response will be to arm up and attack the non-attacking state. In this case, any SPNE involves: immediate war where both players choose arms levels to maximize their expected payoffs in the war. If $m>1$, then this corresponds with the Offensive War scenario described in the previous section. If $m<1$, then this corresponds with the Rope-A-Dope scenario from the previous section.

In addition, we must reconsider the Pyrrhic Victory condition because arming is now an endogenous choice. ${ }^{52}$ An attacker can only succeed with $100 \%$ certainty if the opponent chooses to spend none of its resource endowment on arms. In this case, the attacker could spend some very small $\epsilon>0$ on arms and achieve victory with $100 \%$ certainty. Therefore, the Pyrrhic victory condition in this iteration of the model with endogenous arming and exogenous war costs becomes:

$$
\frac{1+\gamma / 2}{1-\delta}>1+\frac{\gamma-c+\delta(1+\mu)}{1-\delta}
$$

This simplifies to:

$$
c>\frac{\gamma}{2}+\delta \mu
$$

50. Fearon claimed that there are always equilibria where both sides attack because they expect the other side to attack even though this outcome is Pareto dominated by a feasible peaceful outcome (Fearon 2018 , footnote 23). However, this is only the case when offense is advantaged $(m>1)$. When defense is advantaged, states have a higher probability of winning when they are attacked than when they attack, and therefore (attack,attack) is not part of an SPNE.

51. See (Fearon 2018) for more detail on the role of the bargaining process. As with Fearon's original analysis, peaceful equilibria result in symmetric arming and an even split of $\gamma$. As in Fearon's model, the bargaining process only plays a subtle role when states are given the option to attack in that it keeps states from undercutting on military spending, since this would disadvantage them on bargaining. This thus rules out equilibria with random arms levels found in (Jackson 2009), which would significantly complicate our welfare analysis.

52. The Pyrrhic Victory condition in this iteration of the model is the complement of equation 2 from (Fearon 2018) 


\section{Perfectly Patient Players}

To calculate state welfare, we need to calculate arms levels in addition to assessing the decision to attack or not attack. We begin by considering the special case where states are perfectly patient. When $\delta \rightarrow 1$, states will spend all of their resources on arms because the perpetuity payoff from winning war becomes extremely large as players approach perfect patience (formally $\frac{w}{1-\delta} \rightarrow \infty$ when $\delta \rightarrow 1$ ), provided that victories are not Pyrrhic.

We consider how state welfare evolves with increasing offensive advantage in the following proposition and corollaries:

Proposition 2: In the dynamic model with endogenous arming and exogenous war costs that are sufficiently low such that that the Pyrrhic Victory condition does not hold, when players are perfectly patient $(\delta \rightarrow 1)$, state welfare is weakly decreasing under higher offensive advantage (higher $m$ ).

Corollary 2.1: For sufficient defensive advantage (sufficiently small $m$ ), peace is an equilibrium. Welfare is decreasing under higher offensive advantage (higher m) in Pareto optimal peace equilibria as higher arms burdens are required to maintain deterrence.

Corollary 2.2: For sufficient offensive advantage (sufficiently high $\mathrm{m}$ ), war is an equilibrium because states cannot spend enough on arms to deter an opponent from engaging in a predatory attack. War equilibria result in full arming $(a=1)$, and state welfare is unchanged under offensive advantage in the war equilibrium.

Now that we have considered a model with endogenous arming, we can see the mechanism by which greater offensive advantage leads to lower welfare in the peace equilibrium: as offense becomes more advantaged, states are required to spend more of their scarce resources on arms to deter opponents from engaging in a predatory attack against them. As peace becomes increasingly unattractive, the gamble of a predatory attack that can end this costly peace becomes increasingly attractive in comparison. At high enough levels of offensive advantage, the costly peace equilibrium can no longer be supported, and the game switches to a war equilibrium. While welfare in peace equilibria decreases under higher offensive advantage, in war equilibria, welfare remains constant under higher offensive advantage because perfectly patient players spend all of their resources on arms $(a=1)$ and the rest of the variables affecting payoffs are exogenous.

One historical example of this costly peace mechanism comes from Nazi Germany's 1935-1939 rearmament program. This was the largest transfer of resources ever undertaken by a capitalist state in peacetime: German military spending went from $1 \%$ of GNP in 1933 to $20 \%$ of GNP by 1938. Although arming was ultimately undertaken to prepare for wars of conquest to fulfill Hitler's ideological goal of new Lebensraum (living space), historian Adam Tooze provides evidence that arming to this level in 
peacetime made peace increasingly untenable even if Hitler had a change of heart. From the beginning, the trade-off between consumption and armaments was severe: butter and meat were rationed in many German cities starting four years before the war in 1935. Friedrich Fromm, the head of the central administrative office of the German army, asserted in an important memorandum that completing the rearmament program without going to war would have dire economic consequences. Fromm contended that because demand for armaments would fall significantly upon completing rearmament, this now large sector of the economy would have to be painfully converted back to civilian uses, which would both hurt war-readiness and cause economic contraction. In addition, maintaining the readiness of the Wehrmacht required raw materials that were scarce domestically including oil, steel, and rubber. Germany found it difficult to import these materials given balance of payments issues and foreign suspicion of Germany's intentions. Given these factors, Tooze concludes that, "War now had to be contemplated not as an option, but as the logical consequence of the preparations being made." 53

Similarly, after Japan had been unified by Toyotomi Hideyoshi in 1590, Hideyoshi found himself in control of arguably the most powerful army in the world at that time. ${ }^{54}$ This army was well-trained and experienced, as well as large and expensive. After 1590, this great army was was now idle, as all of Hideyoshi's enemies in Japan had been either vanquished or joined Hideyoshi. As in the 1930s Germany case, Hideyoshi was faced with the prospect of either living with a peace burdened by the need to support his vast armies, beating the swords of his armies into ploughshares, 55 or obtaining a return on military investment by using his powerful armies to conquer and subdue new lands in Korea and China. Hideyoshi elected for the latter choice. He thus initiated an invasion of Korea in 1592 where his armies fought both the Koreans and the Chinese in the Imjin War in the Korean peninsula for six years. The war is estimated to have killed at least hundreds of thousands and possibly millions of people. ${ }^{56}$

\section{Imperfectly Patient Players}

Now we consider the case in which states are no longer perfectly patient. This is the more realistic case because wars and their effects in the present have significant

\section{Tooze 2008.}

54. According to (Hawley 2005): "As for Hideyoshi, he possessed the most powerful army that then existed in the world, a quarter-million men and more, battle hardened, superbly armed and led, the Darwinian end product of more than one hundred years of civil war. By way of comparison, the Spanish armada that attacked England a few years before consisted of roughly 30,000 men; the entire army of Queen Elizabeth I was not much more than 20,000. Had he been able to transport his forces to Europe, Hideyoshi could have ground them both into dust."

55. In Hideyoshi's case, this was an especially untenable option because he had been able to subdue many daimyōs without fighting by promising future riches from new conquests. Once Japan was conquered, he had to look beyond Japan for new potential conquests.

56. Hawley 2014. 
weight in the calculation of leaders. Here, states no longer necessarily fully arm in war equilibria. Therefore, we can no longer easily find a solution by assuming that both states are fully arming when analyzing comparative statics. We now must find arms levels that maximize state welfare when war is an equilibrium (the RHS of the dynamic war constraint). To find this solution, however, we must make an assumption for the functional form of the CSF.

In this section, we use a standard functional form for the CSF that satisfies the CSF criteria specified in the appendix. ${ }^{57}$ For an attacker: ${ }^{58}$

$$
p_{o}\left(a_{o}, a_{d} ; m\right)=\frac{m a_{o}}{m a_{o}+a_{d}}
$$

For a defender:

$$
p_{d}\left(a_{d}, a_{o} ; m\right)=\frac{a_{d}}{m a_{o}+a_{d}}
$$

These CSF functional forms have a useful and natural theoretical interpretation: the offense-defense balance parameter $m$ can be interpreted as the ratio of defender to attacker forces that gives the defender a 50:50 chance of victory. For instance, when $m=1$, then equally matched attackers and defenders will have a 50:50 chance of victory. When $m=1 / 3$, attackers require $3 \mathrm{x}$ the arms levels of defenders in order to have a 50:50 chance of winning, implying defensive advantage. When $m=3$, defenders require $3 x$ the arms levels of attackers in order to have a 50:50 chance of winning, implying offensive advantage.

When both players simultaneously attack, we assume a "coin flip" CSF, i.e. there is a $50 \%$ chance that a given side ends up on the attack and a $50 \%$ chance they end up on the defense. Formally, when player i simultaneously attacks player j, player i's chance of winning is:

$$
p_{s}^{i}\left(a_{i}, a_{j} ; m\right)=\left(\frac{1}{2}\right)\left(\frac{m a_{i}}{a_{i}+m a_{j}}\right)+\left(\frac{1}{2}\right)\left(\frac{a_{i}}{m a_{i}+a_{j}}\right)
$$

Solving this dynamic model with endogenous arming demonstrates that welfare is $\mathrm{u}$-shaped in offensive advantage. We summarize the results in following propositions and corollaries.

Proposition 3: In the dynamic model with endogenous arming and exogenous war costs that are sufficiently low such that the Pyrrhic Victory Condition does not hold, and where players place sufficient value on the present period relative to future periods ( $\delta$ is sufficiently small) such that there is partial arming in equilibrium $a \in(0,1)$, state welfare is u-shaped under offensive advantage (WUO) in equilibrium.

57. Fearon also suggests this functional form for an attacking country's CSF: Fearon 2018 equation 1. 58. $a_{o}$ specifies attacker arms levels and $a_{d}$ specifies defender arms levels. 
Corollary 3.1: For sufficient defensive advantage (sufficiently small $m$ ), peace is an equilibrium. Welfare is decreasing under higher offensive advantage in Pareto optimal peace equilibria as higher arms burdens are required to maintain deterrence.

Corollary 3.2: For sufficient offensive advantage (sufficiently high $m$ ), war is an equilibrium because states cannot spend enough on arms to deter an opponent from engaging in a predatory attack.

Corollary 3.3: In war equilibria with partial arming, welfare continues to decrease in offensive advantage when defense remains advantaged $(m<1$, which implies the rope-a-dope scenario), but welfare increases in offensive advantage in the war equilibria when offense becomes advantaged ( $m>1$, which implies the offensive war scenario). When $m<1$, war equilibria with partial arming occur when $\frac{[\gamma-c+\delta(1+\mu)]}{(1-\delta)}<\frac{(m+1)^{2}}{m}$. When $m>1$, war equilibria with partial arming occur when $\frac{[\gamma-c+\delta(1+\mu)]}{(1-\delta)}<2(m+1)$.

Corollary 3.4: Even though the war remains decisive in the model (one side is eliminated in perpetuity), higher offensive advantage causes wars to be less total in equilibrium when $m>1$ (a lower fraction of state resources are spent on arms levels), which increases state welfare.

These results are the first time in this analysis in which increasing advantage does not lead to weakly worse outcomes. Increasing offensive advantage is still welfare decreasing in peace because higher arms burdens are required to deter a potential predatory attack as offense is more advantaged. In the war equilibrium, however, we see that increasing offensive advantage can increase welfare when $m>1$. This is because under higher levels of offensive advantage, their is lower marginal benefit to arming. Under partial arming, states choose their arms levels such that the marginal benefit of arming - a marginally higher probability of winning the war - is equal to the marginal cost, which is fixed at 1 since 1 extra unit of the endowment devoted to arms is 1 less unit of the endowment available for consumption (see Appendix for formal details). Note that if the costs of war are sufficiently high such that the Pyrrhic Victory condition holds, then war is never an equilibrium and this result does not hold.

The intuition for this result is straightforward: as offense becomes increasingly advantaged away from offense-defense neutrality at $m=1$, differences in relative arms levels become less important compared to who ends up being on the offensive. While a marginal investment in arms increases the probability of winning no matter how advantaged the offensive is, military investments yields the highest returns when the offense-defense balance is closest to offense-defense neutrality. Therefore, when there is a partial arming equilibrium, equilibrium arms levels are highest when the offense-defense balance is closest to offense-defense neutrality, and are lower with increasing offensive advantage above offense-defense neutrality. Lower arms burdens increase consumption, which leads to increasing welfare under increasing offensive advantage.

In short, the closer the offense-defense balance is to offense-defense neutrality, 
the higher the returns to arms and the higher the equilibrium arms levels. This has the result of increasing arms levels and decreasing welfare under increasing offensive advantage in war equilibria when $m<1$ and decreasing arms and increasing welfare under increasing offensive advantage in war equilibria when $m>1$. The broader international relations interpretation of this result is that wars with high levels of offensive advantage tend to be less total and more limited compared to wars in which there is offense-defense neutrality. At higher levels of offensive advantage, states feel less compelled to devote a large fraction of their resources to war when the outcome of the war is more determined by which side is on the offensive compared to which side has the higher relative arms levels. This results in less total wars and higher welfare. ${ }^{59}$

In the appendix, we derived an analytical solution to the model, and the WUO result is shown in figure 4.

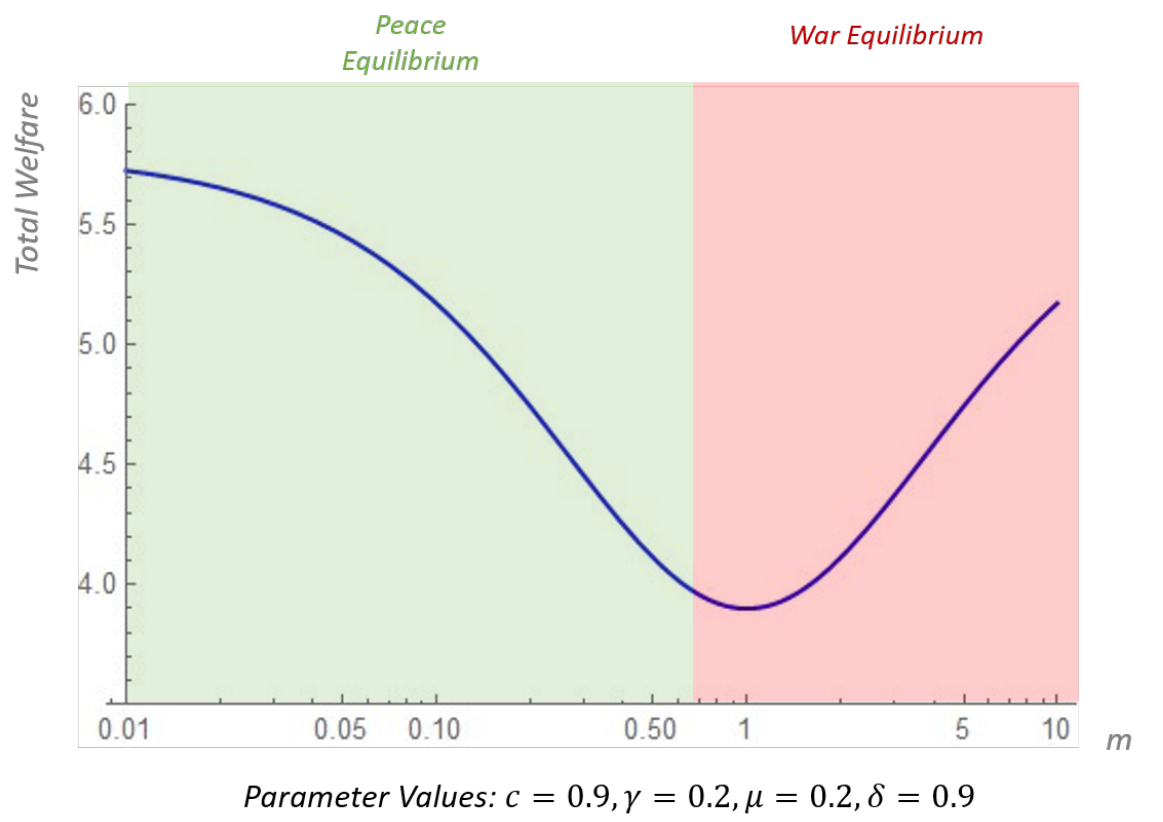

FIGURE 4 Total Welfare is u-shaped under increasing offensive advantage.

We can see this mechanism in action during the Napoleonic Wars. As discussed

59. In this section, the cost of war remain exogenous, so this result is only due to the higher consumption that results from lower arms burdens. However, a reasonable assumption would be that the costs of war are increasing in state arms burdens (i.e. more total wars tend to also be more costly). This would further magnify this result, but it would significantly complicate the model and our ability to find an analytical solution to the model. 
in the previous section, offense was more advantaged in the France-Austria dyad and the France-Prussia dyad compared to the France-Russia Dyad in the early 1800s, primarily due to geographic factors: living off of the land was easier in the richer and more agriculturally dense Central Europe, the roads were much better to support fast troop movements, and the geographic distances, especially to enemy capitals, were much closer, making it easier for an attacker to force a defender into a decisive battle on their terms. In his campaigns in Central Europe against Austria and Prussia in the Wars of the Third and Fourth Coalitions, Napoleon immediately attacked his enemies deep in their territory with the army he had at the time. ${ }^{60}$ In the War of the Third Coalition against Austria, Napoleon used the army that he had assembled in Boulogne for a planned invasion of Britain in a series of furious marches towards Austria. He invaded with an army of 210,000 winning decisive victories at Ulm and Austerlitz. He defeated the Austrians and occupied Vienna in just over two months from the beginning of the campaign. ${ }^{61}$ Similarly, in the war of the Fourth Coalition against Prussia, Napoleon immediately invaded Prussia with the part of his army that remained east of the Rhine River after his victories over Austria in the previous year. Invading with 160,000 men, ${ }^{62}$ he won decisive victories in the twin battles of Jena-Auerstadt and took Berlin just 19 days after the initial invasion. ${ }^{63}$

In his 1812 invasion of Russia, by contrast, Napoleon did not strike Russia as fast as possible with the army he had. He was well aware of the difficulties a Russian invasion posed relative to Central European warfare. He told his stepson Eugene: "war in Poland [Russia] in no way resembles war in Austria; without means of transport, everything is useless." He told his Marshal Davout "We can hope for nothing from the countryside and accordingly must take everything with us." 64 Napoleon was hoping that the Russians would give battle quickly close to the border of the Duchy of Warsaw, but he did speculate that they may very well refuse. From the beginning, Napoleon was planning for the contingency that the war would drag on much longer than he hoped: he told his allies and his staff that he was prepared to pursue the Russians as far as Smolensk, and then take up winter quarters in Vilnius and continue the war in $1813 .{ }^{65}$

With the possibility of a long and drawn out war, Napoleon did not take the army he had to quickly strike Russia, but instead focused on building up his army to gain force superiority. In what he believed could end up being a longer and slower-moving campaign, the daring initiative and fast movement that had been instrumental to his

60. In both wars, Russia fought on the side of Austria and Prussia respectively, but the fighting took place primarily on Austrian and Prussian territory.

61. Chandler 2009.

62. Chandler 2009.

63. King Frederick William III of Prussia continued to fight on with his Russian allies in East Prussia after losing most of his army to the French. This fighting involved mostly Russian troops on Prussian territory, and France ultimately prevailed after Napoleon's victory at Friedland in 1807.

64. Mikaberidze 2016.

65. Jomini 1975. 
victories in Central Europe were now less feasible, and obtaining force superiority was a more crucial factor in achieving victory. In 1812, Napoleon created the largest army in the history of Europe up to that point, numbering 685,000 men, and three times larger than any he had commanded before. He spent the first half of 1812 provisioning for this massive invasion army and building logistical capacity in Poland and East Prussia and supply routes to the Rhine in preparation for the invasion, which was launched in June. With this army, Napoleon did indeed achieve force superiority: his massive Grande Armée initially faced a defense of 190,000 on the Russian side. In total, 428,000 troops would come into action on the Russian side in 1812. ${ }^{66}$ Despite French force superiority, the Russians were able to make use of their natural defensive advantages by avoiding a decisive battle, utilizing scorched-earth tactics to further deny the Grande Armée provisions, and harrassing the Grande Armée with Cossack cavalry. The provisioning of supplies that Napoleon had carefully orchestrated went worse than expected as wagons struggled to move along muddy roads and horses were dying due to lack of fodder. Once on campaign, Napoleon was more aggressive than his original plan, as he continued marching past Smolensk towards Moscow when the enemy had still not been decisively defeated. Despite the lack of major engagements, the Grande Armée army took heavy casualties from disease and exhaustion. The Russian army did finally give battle at Smolensk and Borodino, with Napoleon winning the field on both occasions, but the Russian army retreating in good order. Although Napoleon took Moscow, the Russians burned down much of the city and refused to surrender. Facing the coming Russian winter, Napoleon retreated and his troops suffered in freezing temperatures all the while being harassed by Cossacks. By the end of the campaign, the majority of the Grande Armée had died, deserted, or were captured. Napoleon's invasion of Russia was indeed larger in scale than any of his previous campaigns, and it was also by far his costliest campaign.

In summary, we see that when fighting in the Central European territory that favored offensive warfare, obtaining the initiative on offense was more important than obtaining force superiority. Napoleon's focus was on striking the enemy in their territory as quickly as possible as opposed to building up his forces to be as large and as supplied as possible. Napoleon's Central European campaigns were less costly because offensive advantage meant the need for fewer troops just as the logic of Proposition 3 and corollary 3.3 predict. In addition, the fighting was quick and and decisive, a dynamic we study more below. In Russia, however, offense was less advantaged due to geographical factors, and therefore force superiority was more important than taking the offensive and striking quickly in a war of movement. Napoleon thus took considerable time to invest in force superiority before invading Russia in 1812. Because the invasion involved a larger number of troops and the campaign was drawn out in the larger and poorer country that exposed his men to harsher conditions, this campaign was by far Napoleon's costliest. 


\section{A Dynamic Model with Endogenous Arming and Exogenous War Costs}

In this section, we take the dynamic model with endogenous arming and exogenous war costs from the previous section with one change: we make war costs endogenous. We do this by considering the war as a series of operations that are either decisive or result in a stalemate that causes the war to continue into further operations. In the previous section, we considered war in a reduced form way with a single contest success function and a single exogenous war cost value. In this section, each operation is associated with a cost, so the greater the number of operations, the higher the total cost of the war.

The advantage of this approach is that it integrates operational-level and strategiclevel conceptions of the offense-defense balance. In past literature, Biddle (2001) argued that the operational level is the most appropriate level of analysis for assessing the offense-defense balance, whereas Glaser and Kaufman (1998) argue that the strategic level - i.e. the level of the outcome of the war - is the more appropriate level of analysis. So far, we have been only considering the effect of the offensedefense balance on the strategic level. In this section, we consider the effect of the offense-defense on the operational level, which ends up having effects at the strategic level.

\section{Modelling Military Operations}

The probability that a given operation ends decisively for player $\mathrm{i}$ is given by the $\operatorname{CSF} \pi_{i}\left(a_{i}, a_{j} ; m\right)$. We assume that $\pi_{i}\left(a_{i}, a_{j} ; m\right)$ has the same properties as the $\mathrm{CSF} p_{i}\left(a_{i}, a_{j} ; m\right)$ discussed in the appendix. The one exception is that property $8, \pi_{i}+\pi_{j}=1$, does not necessarily hold because there is also some probability $\pi_{s}\left(a_{i}, a_{j} ; m\right)$ that the operation bogs down into a stalemate and that the war continues into the next period with another operation. Instead, we assume that an operation results in one of three outcomes: decisive victory for $i$, decisive victory for $j$, or a stalemate that results in the war continuing to another operation in the next period, and thus $\pi_{i}+\pi_{j}+\pi_{s}=1$.

We assume that when offense is more advantaged, operations have a higher probability of being decisive, i.e. $\frac{\partial \pi_{s}}{\partial m}<0$. In addition, we assume that the total cost of war, $c$, is linearly increasing in the number of operations where each operation has cost $k$. If the war involves one operation, then the cost of the war is $k$. If the war involves two operations, then the cost of the war is $2 k$. If it involves 3 operations, the cost of the war is $3 k$, and so on. ${ }^{67}$

67. These assumptions are consistent with arguments made in a large body of past literature. James Fearon claims: "I argue that the best way to assess whether offense or defense dominates is to look at the evidence provided by the wars themselves. If wars last a long time and see many attrition contests but few decisive battles between roughly equal adversaries, then defense dominates. If wars are short and characterized by decisive battles between roughly equal opponents, offense dominates." (Fearon 1995) 
A summary of the war model is shown in the tree below:

FIGURE 5. Extensive Form War Model

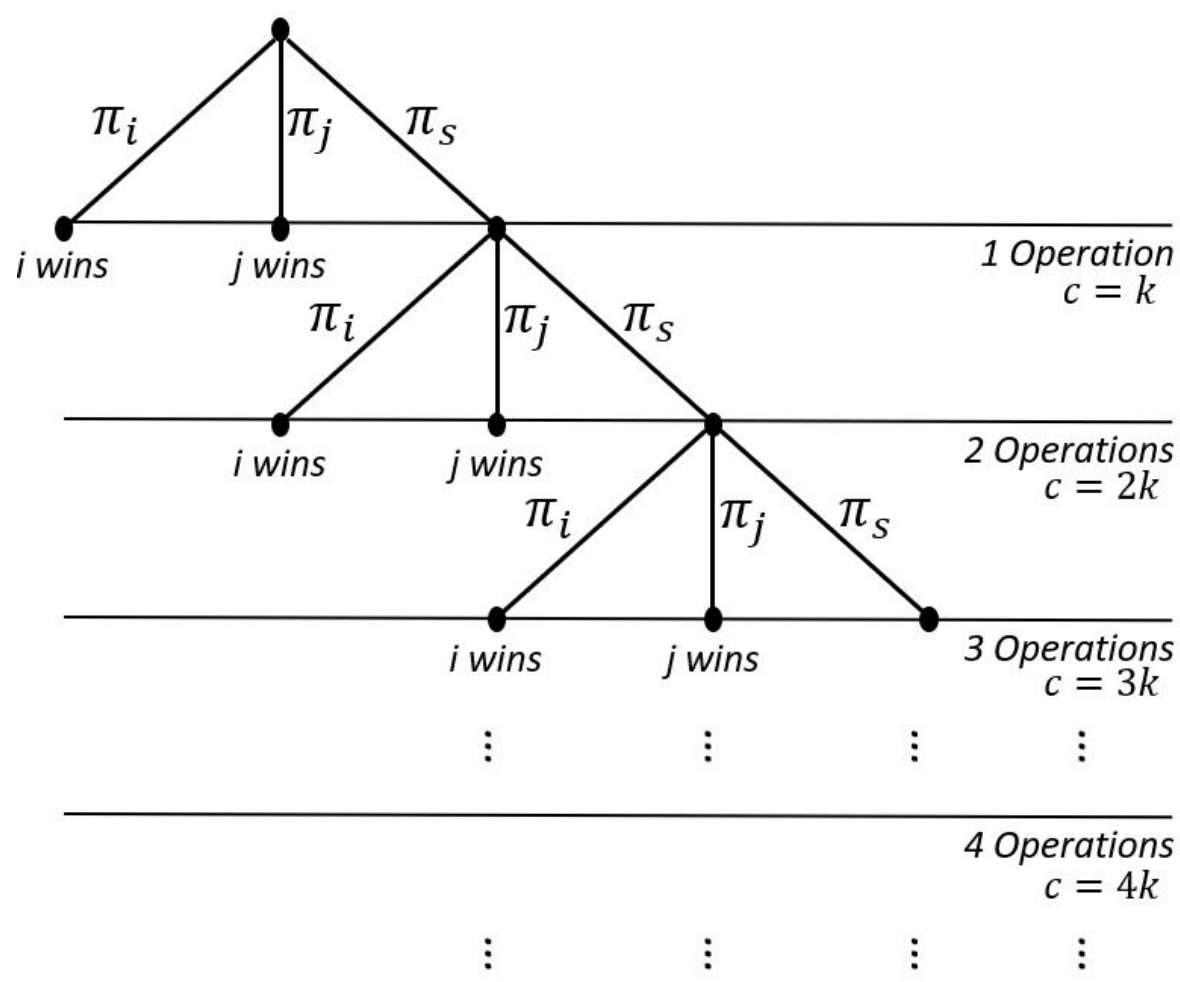

The expected war cost is an increasing linear function of the number of operations, where the cost of each operation is $k$. The expected cost of the war is equal to: $c=k+\pi_{s} k+\pi_{s}^{2} k+\pi_{s}^{3} k+\ldots$. Notice that this is a geometric series, so we can simplify the expected war cost to:

$$
c=\frac{k}{1-\pi_{s}}
$$

From this equation, we can see that the expected war cost is increasing in $\pi_{s}$ : the

Similarly, Charles Glaser and Chaim Kaufman argue that under offensive advantage, "war will be quick and decisive and therefore profitable". (Glaser and Kaufmann 1998) Robert Jervis argues that "When there are incentives to strike first, a successful attack will usually so weaken the other side that victory will be relatively quick, bloodless, and decisive" and "When defense is dominant, wars are likely to become stalemates and can be won only at enormous cost" (Jervis 1978). 
more likely that operations are to bog down into stalemate, the higher the expected cost of war.

In order to achieve an analytical solution to the model, we add a few additional assumptions. First, we assume that the probabilities of decisive victory $\pi_{i}$ and $\pi_{j}$ are equal to the CSFs $p_{i}\left(a_{i}, a_{j} ; m\right)$ and $p_{j}\left(a_{i}, a_{j} ; m\right)$ respectively scaled by a common decisiveness factor $d \in(0,1)$. Recall we assumed that a given operation can result in one of three outcomes: decisive victory for $\mathrm{i}$, decisive victory for $\mathrm{j}$, or a stalemate that results in the war continuing to another operation in the next period, i.e.:

$$
\pi_{i}\left(a_{i}, a_{j} ; m\right)+\pi_{j}\left(a_{i}, a_{j} ; m\right)+\pi_{s}=1
$$

Rewriting:

$$
d * p_{i}\left(a_{i}, a_{j} ; m\right)+d * p_{i}\left(a_{i}, a_{j} ; m\right)+\pi_{s}=1
$$

Recall that the CSF assumption 8 in the appendix states that $p_{i}\left(a_{i}, a_{j} ; m\right)+$ $p_{j}\left(a_{i}, a_{j} ; m\right)=1$. Applying this to the above equation:

$$
\pi_{s}=1-d
$$

Finally, we assume that the probability that an operation bogs down in a stalemate is given by the functional form:

$$
\pi_{s}=\frac{1}{m+1}
$$

We can see that this is natural: consider a case where offense is advantaged by some factor $x$, i.e. $m=x$. Also consider a case where defense is advantaged by the same factor, i.e. $m=\frac{1}{x}$. We can see that the probability of stalemate in the first case is equal to one subtracted by the probability of stalemate in the second case, i.e. $\pi_{s}(m=x)=1-\pi_{s}\left(m=\frac{1}{x}\right)$. E.g. if offense has a 10:1 advantage, i.e. $m=10$, then the probability of stalemate is relatively low: $\pi_{s}=\frac{1}{11}$. If defense has a 10:1 advantage, i.e. $m=\frac{1}{10}$, then the probability of stalemate is relatively high and given by $\frac{10}{11}$, which is equal to $1-\frac{1}{11}$. This functional form fixes the probability of stalemate in offense-defense neutrality at $50 \%$, i.e. when $m=1, \pi_{s}=\frac{1}{2} \cdot{ }^{68}$ form:

Combining equations 8 and 9 , we can solve for endogenous war costs in reduced

$$
c=k\left(\frac{m}{m+1}\right)
$$

Note that because $\pi_{s}<1,\left(\pi_{s}\right)^{t}$ converges to 0 as $\mathrm{t} \rightarrow \infty$. Because the chance of winning the operation $\pi_{i}$ and $\pi_{j}$ are scaled by the common factor $d$, the war model and note that our results will retain the same directionally regardless of the scaling factor we choose. 
does not end up changing the probability that players $i$ and $j$ end up winning compared to the reduced-form CSFs that we considered until this section. These implications allow us to embed the war model into the setting we analyzed in the previous section using equation 10 for war cost.

Given the way we model operations, the offense-defense balance at the operational level implies the same offense-defense balance at the strategic level and vice versa. This is because we assume that the attacker in the first operation continues to be the attacker in all subsequent operations and the same offense-defense balance applies in every operation. Irrespective of how we choose to model operations, however, offensive advantage at the operational level also implies offensive advantage at the strategic level because the attacking country is the attacker in at least the first operation. Alternatively, we could have modeled operations in such a way that the attacking country is the attacker in the first operation, but in subsequent operations, the attacker is determined randomly using the coin-flip CSF we discussed earlier. ${ }^{69}$ This would yield the same directional results, but would complicate the analysis. ${ }^{70}$.

Because the cost of war is now endogenous to the offense-defense balance in this version of the model, we must replace $c$ in equation 4 with $k\left(\frac{m}{m+1}\right)$ to find the new Pyrrhic victory condition:

$$
k\left(\frac{m}{m+1}\right)>\frac{\gamma}{2}+\delta \mu
$$

Now, the Pyrrhic victor condition depends on the offense-defense balance in addition to the cost of a military operation $(k)$. If the offense-defense balance heavily favors offense (large $m$ ), then the cost of a military operation must be quite high for the Pyrrhic victory condition to hold since there will likely be only a single decisive operation in the event of war. On the flip-side, if the offense-defense balance heavily favors defense (i.e. $m$ is near 0 ), then the Pyrrhic victory condition may hold even when the cost of a military operation is modest because the expected number of operations in a war is quite high.

69. Arguably, this would more accurately describe the historical record. For instance, the Germans attacked the Soviet Union in the first Operation of the war in Operation Barbarossa. They were on the attack in some subsequent operations such as Case Blue in Southern Russia in 1942 and Operation Citadel in Central Russia in 1943, but the Soviets also launched their own offensive operations such as the December 1941 counterattack outside Moscow, the 1942 Operation Fredericus (the Second Battle of Kharkov) and the 1942 Operation Mars attack on the Rzhev-Vyazma salient. After Operation Citadel, the Soviets were mostly the side that was conducting offensive operations such as the Dnieper Offensives in 1943 and Operation Bagration in 1944.

70. If there is a high level of offensive advantage and the attacker only enjoys this offensive advantage in the first operation before reverting back to a random chance of being on the attack in subsequent operations, the attacker still receives the benefits of offensive advantage, although the magnitude of this benefit is smaller because the attacker is not guaranteed to be on the offensive in subsequent operations. In addition, past literature has emphasized that states decide to initiate wars when they believe that they can decisively achieve victory in the first operation, so the offense-defense at the operational level is the crucial factor in the decision to go to war (Biddle 2001). As Sun Tzu stated: "A speedy victory is the main object in war" (Tzu 2008) 
In the previous iteration of the model with exogenous war costs, higher offensive advantage increased welfare in war equilibria only when offense was advantaged $(m>1)$ and when players placed some value on the present relative to the future $(\delta<1)$. In this version of the model, endogenous wars costs that are increasing in offensive advantage cause welfare to be increasing in offensive advantage in all war equilibria even when $\delta$ approaches 1 , provided that $m>1$. If $m<1$, increasing offensive advantage decreases war costs, which increases welfare, but equilibrium arms levels are also increasing under offensive advantage up to $m=1$, which decreases welfare. The net effect of these two countervailing mechanisms on welfare depends on values for the exogenous variables in the model. Because welfare increases in offensive advantage in all scenarios when $m>1$, this guarantees that WUO holds even when $\delta \rightarrow 1$. We summarize this result in the following proposition:

Proposition 4: In the dynamic model with endogenous arming and endogenous war costs, welfare is u-shaped under offensive advantage - decreasing in peace equilibria and increasing in war equilibria for sufficiently high offensive advantage under all patience and arming scenarios provided that the cost of military operations is sufficiently low such that the Pyrrhic Victory Condition does not hold.

To summarize, we now have three mechanisms that contribute towards WUO:

1. In the peace equilibrium, increasing offensive advantage reduces state welfare because higher arms burdens are required to deter the other side from attacking (introduced in proposition 2).

2. In the war equilibrium, increasing offensive advantage to high levels causes wars to be less total and smaller in scale due to lower returns to arms investment (introduced in proposition 3).

3. Wars tend to be faster and more decisive under higher offensive advantage, which reduces the cost of war (introduced in this section).

The dynamic model in this section with endogenous arming and endogenous war costs captures all three of these mechanisms and guarantees that the WUO result holds regardless of patience $(\delta)$, as captured in proposition 4 . This leads us to the final proposition:

Proposition 5: Provided that the cost of military operations is sufficiently small such that the Pyrrhic victor condition does not hold, non-marginal shocks to the offense-defense balance in favor of attackers can cause an absolute increase in state welfare by switching from a costly peace equilibrium burdened by high arms levels to 
maintain deterrence to a decisive war equilibrium.

Proposition 5 suggests that shocks to military technology and organization that increase offensive advantage can improve welfare by switching from a costly peace equilibrium burdened by high arms levels to maintain deterrence to a war equilibrium in which war is made less costly by more decisive wars and lower returns to arms spending. ${ }^{71}$ Note that proposition 5 only holds provided that the costs of war are sufficiently small such that victories are not Pyrrhic.

The intuition for this result is straightforward: anarchy is costly not only when war is an equilibrium due to the costs of war, but also when peace is an equilibrium due to the foregone consumption that must go towards arms spending to deter the other side from a predatory attack. States can avoid these peace-time costs of anarchy in all future periods by eliminating the other side in a war.

In short, war is inefficient, but so is a costly peace. A large exogenous increase in offensive advantage due to some change in military technology, for instance, can provide the spark for states to engage in a decisive war that results in no more future costs of anarchy because there is no more anarchy. This outcome can be welfare-improving over a continued costly peace.

To draw an analogy to business, some aspiring monopolists such as John D. Rockefeller in the 1870 s would proactively engage in costly price wars with their competitors. While such actions were costly in the short-run, they would often be profitable over the long-run because they would drive competitors out of business and avoid future costs of competition. After the consolidation of the industry into a single monopoly, the total economic rents to the industry increase relative to when the industry had competitors because the monopoly industry is now a price maker that charges the price that maximizes industry profitability instead of a price taker where the market price is determined by competitive forces.

Compared to war (or price war), a potentially better solution would be for states (or companies) to voluntarily choose to federate (or merge) instead of engaging in a costly war to avoid future costs of competition. This would allow states to forego the future costs of anarchy by removing the state of anarchy while also avoiding a costly war. For reasons discussed in past literature on conflict resolution and power-sharing agreements after civil wars, however, this is often not an equilibrium due to commitment problems that arise from power-sharing agreements and nationalist preferences. ${ }^{72}$

The Japanese and Chinese Warring states period provide historical evidence showing how innovations that favored the offense allowed single rulers to conquer and consolidate the country, ending centuries of costly anarchy and leading to peace and

71. Proposition 5 also follows from the dynamic model with endogenous arming and exogenous war costs introduced in the previous section, but only in the case where $\delta<1$.

72. Alesina and Spolaore 2005; Fearon 2011. 
greater prosperity. In the early Sengoku Jidai (the Japanese Age of Warring States, 1467-1600), the country dissolved into hundreds of independent states run by warlords (daimyōs). Armies usually consisted of conglomerations of small independent bands of warriors that rarely numbered more than a few dozen. These bands temporarily allied themselves with warlords for the promise of achieving predetermined rewards. ${ }^{73}$ Because it was difficult to keep an army intact, warlords were unable to conquer and pacify large amounts of new territory, and Japan remained in a period of warring states for over a hundred years. However, by the late Sengoku period, three warlords Oda Nobunaga (1534-1582), Toyotomi Hideyoshi (1537-1598), and Tokugawa Ieyasu (1542-1616) - revolutionized military organization and utilized new technologies so that it was possible to conquer large swaths of territory and to ultimately consolidate Japan into a single state. These leaders created large, professional, and permanent armies so that they no longer needed to rely on the transactional and temporary services of small bands of warriors. Networks of castles had been built by warlords across Japan, and for much of the Sengoku period, it was difficult for armies to conquer these fortifications. Toyotomi Hideyoshi was able to nullify the defensive advantages provided by castles through his effective use of new siege cannons, as firearms were introduced to Japan in the mid 16th century. By the end of the 16th century, Hideyoshi was able to subdue enemy castles quickly and usually with few casualties by using his siege cannons combined with isolation sieges. ${ }^{74}$ Due to these innovations that favored the offense and made it viable to conquer and hold large swaths of territory, these three rulers were able to conquer and consolidate large parts of Japan. Japan was ultimately unified under the rule of Tokugawa Ieyasu in 1600 after he won the battle of Sekigahara in 1600. This led to the prosperous and peaceful Edo period (1600-1868). In this case, the increase in offensive advantage in the late Sengoku period led to a better outcome for Japan by ending over a hundred years of warring states.

China endured a bloody period of warring States much earlier in its history, from 475-221 BC. The Chinese Warring States period has remarkable similarities to the Sengoku period in terms of the development of military organization and technology that favored the offense and contributed towards one state consolidating the entire region under its rule, ending centuries of costly anarchy. At the beginning of the period, fortifications were nearly impregnable. Towards the end of the period, however, siege-engines including battering-rams, catapults, and rolling towers were introduced that could subdue the strongest fortifications available at that time..$^{75}$ Also, like in the Sengoku period, states created permanent large professional armies that replaced more informal feudal armies, which could more easily conquer and hold territory and were less likely to desert. The two largest states at the end of the period had armies numbering in the millions. ${ }^{76}$ Aided by these innovations that favored the offense, Qin

73. Conlan 2001; Stavros 2013.

74. Stavros 2013.

75. Andreski 1968.

76. Van Evera 1998. 
Shi Huang was able to put an end to the Warring States period by rapidly conquering the seven other kingdoms one-by-one over the span of only nine years in 230-221 BC. After the war of unification, the emperor pursued policies that were aimed at standardizing practices across the country, connecting the country with roads, and creating a strong national identity. Qin Shi Huang himself emphasized that the purpose of his conquest was to create peace by bringing all under heaven (Tianxia in Chinese) under one ruler so that spending on arms was no longer necessary. As he inscribed in a stone carving on a sacred mountain: "The emperor brought peace to all under heaven. . . (so that) people are at peace, never needing to take up arms." 77 This narrative continues to be culturally important in China: the popular 2002 Chinese movie Hero portrays an assassin during Qin's wars of unification that is sent to kill Qin Shi Huang. While in conversation with the emperor, the assassin realizes that despite the emperor's bloody wars, he will ultimately unite the warring lands and bring about long-lasting peace, and therefore the assassin decides to spare the emperor.

\section{Conclusion}

Using the results of our model, we have argued that states are not strictly worse off as offense becomes more advantaged; we show that state welfare is actually $\mathrm{u}$-shaped under increasing offensive advantage $(W U O)$. The three mechanisms that drive WUO are: (1) In the peace equilibrium, increasing offensive advantage reduces state welfare because higher arms burdens are required to deter the other side from attacking. (2) Increasing offensive advantage to high levels causes wars to be less total and smaller in scale due to lower returns to arms investment. (3) Wars tend to be faster and more decisive with higher offensive advantage, which reduces the cost of war.

Our analysis implies that strong defensive advantage is the best outcome because predatory attacks require overwhelming force superiority to have a reasonable chance of succeeding, and thus deterrence against foreign invasion can be maintained at relatively low cost. Although the condition of anarchy remains in this scenario, it imposes little cost. Provided that the costs of war are sufficiently low, the second-best outcome in our model is strong offensive advantage. Even though wars are more likely to occur when offense is highly advantaged, ${ }^{78}$ wars are swifter, smaller in scale, more decisive, and less costly. Once one side achieves a decisive victory, they remove the condition of anarchy by consolidating all of the territory under a single political entity and thus remove the costs of anarchy in future periods. After this consolidation, arms are no longer required to maintain deterrence against an attack or to attack the other side. Historically, the warring states periods in Japan and China followed this pattern as the bloody Sengoku Jidai in Japan led to the prosperous Edo period once all of

\section{Sima 1993.}

78. By "likely," we mean that war is the only equilibrium under a greater range of parameter values in our model. 
Japan was unified under the Tokugawa Shogunate and as the Warring States in China were unified under the rule of Qin Shi Huang, which soon thereafter ushered in the prosperous Han dynasty period.

In summary, strong defensive advantage is first-best, strong offensive advantage is second-best, and the worst outcome is when neither offense nor defense has the upper hand. In this situation, wars are larger in scale, longer, less decisive, and more destructive. When peace can be maintained, high arms burdens are required to deter the other side from a predatory attack. From this middle level of the offensedefense balance, an exogenous shift in either the defensive or the offensive direction is welfare-improving. If defense becomes more advantaged, then war is less likely and lower arms burdens are required to maintain deterrence. If offense becomes more advantaged, then war is more likely, but it will be swifter, smaller in scale, more decisive, less costly, and the resulting consolidation removes future costs of anarchy.

One important implication of our analysis is that it is advantageous to have political consolidation within geographical areas that have internal offensive advantages but external defensive advantages. For example, it is generally welfare-improving when an island is consolidated into a single state. This implies that the Union between England, Scotland, and Wales was a good thing for the welfare of the people of the island of Great Britain ${ }^{79}$ and that the consolidation of the island of Honshu at the end of the Sengoku Jidai was a good thing for the people of Japan. It also implies that geographic areas with natural external barriers - such as China which has the South China Sea on its eastern border, the Gobi desert to the northwest, and the Himalayas to the Southwest and Italy which has the Alps to the North and the Mediterranean surrounding the rest of its borders - are also better off when consolidated under a single state. This implies that Qin Shi Huang's conquest of China was good for the Chinese people and Rome's conquest of Italy completed in the 3rd century BC and the unification of Italy in 1870 were also good for the Italian people.

Our analysis does not imply that conquering and consolidating the whole world into a single political entity would be welfare improving. It is difficult to project power across oceans, islands, large mountain ranges, and other geographical features that favor defense. In addition, if war is excessively costly (i.e. the Pyrrhic victory condition holds), then attacking is a never best response regardless of the offensedefense balance. Today, all five permanent members of the UN Security Council and four other countries possess nuclear weapons, in addition to many other countries that are covered by extended deterrence. This suggests that the Pyrrhic victory condition may currently hold for a large portion of the world's countries. This is good news if future technological developments - such as the development of new cyberweapons or AI-enabled weapons - increase offensive advantage; as long as the Pyrrhic victory condition holds, attacking is a never-best response even as military technology skews

79. This is also argued by John Jay in Federalist papers 4 and 5 (Hamilton, Madison, and Jay 2008). 
the balance towards offense. ${ }^{80}$

It is important to note the limits of the scope of our analysis.

First, one could conclude from our analysis that increasing the cost of war is often good because increasing the cost of war enough causes the Pyrrhic victory condition to hold, which implies that war is never an equilibrium and there is no need for arming. This is similar to Kenneth Waltz's argument in favor of nuclear proliferation. ${ }^{81}$ However, our model does not capture a number of countervailing factors against this line of argument such as the probability of accidental nuclear war, ${ }^{82}$ the externalities of a nuclear conflict on other countries, ${ }^{83}$ an increased likelihood of war from attacks against countries that are in the process of building nuclear weapons (e.g. the 1981 Israeli attack on Osirak in Iraq, the 2007 Israeli attack on Al-Qibar in Syria, and the 2000s US/Israeli Stuxnet cyberattack on Natanz in Iran), and the dangerous period where one side is nuclear capable but does not yet have a credible second strike and other countries may consider a preemptive counterforce strike (e.g. the US considering a "bloody nose" attack on North Korea in 2017).

Second, we do not consider all of the benefits of political competition nor all of the costs of political consolidation. Some historians have argued that the rivalry and conflict between city states in Ancient Greece and Renaissance Italy contributed towards their great cultural achievements. ${ }^{84}$ As the philosopher G.W.F. Hegel argued: "Wars are terrible, but necessary, for they save the state from petrifaction and stagnation." ${ }^{85}$ Furthermore, greater political concentration can also be dangerous. If a bad regime takes power, greater consolidation of territory and power can make the regime more entrenched.

Third, our analysis does not consider that states may federate, and thus gain the benefits of consolidation while avoiding the costs of war. In the Federalist Papers 3-8, Alexander Hamilton and John Jay make similar arguments to the arguments presented in this paper around the benefits of a centrally governed United States versus the states being governed as separate countries. They argue that if the United States were to become separate countries, they would constantly be at war with each other and they would need to spend significant resources on standing armies. This would be not only expensive and burdensome, but states constantly at war or in fear of war would be willing to give up personal liberties to enhance their security. ${ }^{86}$ Personal

80. New technologies that limit the effectiveness of nuclear weapons, such as effective missile defense systems, would counteract this effect.

81. Waltz 1981.

82. Sagan 1995.

83. Jägermeyr et al. 2020.

84. Lines, Laureys, and Kraye 2015.

85. Cashman and Robinson 2007.

86. John Jay, Federalist 5: "Should the People of America divide themselves into three or four nations, would not the same thing happen? Would not similar jealousies arise; and be in like manner cherished? Instead of their being joined in affection, and free from all apprehension of different 'interests,' envy and jealousy would soon extinguish confidence and affection, and the partial interests of each confederacy, 
liberties and freedoms are other factors not considered by our model, but which also affect welfare. Consolidation through Federation is superior to consolidation through conquest because it avoids the cost of war. However, our model suggests that if consolidation through federation is not possible, consolidation through conquest can still be better than a continued costly and risky piece. This suggests that, separate from the immorality of slavery, it was worth it to fight the American Civil War just for the purpose of keeping the Union together, which was Lincoln's primary stated motivation for fighting the Civil War before he announced the Emancipation Proclamation in September 1862.

Finally, the offense-defense balance is treated as exogenous for analytical tractability, but in reality, the historical record suggests that the offense-defense can change over the course of a war and between wars as a strategic response. For instance, when defense is strong, militaries innovate so that offense can become more viable. For instance, the year 1915 was a bad year for offense on the Western Front of World War I (as discussed in the main text). All of the offensives that year on the Western Front failed with high attacker:defender casualty ratios and very little ground taken. However, a number of subsequent technological, tactical, and strategic innovations made offense much more viable by 1918. In the Spring of 1918, the Germans made large advances by combining Stoßtruppen (shock troop) tactics with improved artillery tactics like creeping barrage. Their Spring Offensive nearly achieved its strategic objectives of capturing the Amiens railway, pushing the British out of the Ypres salient, and taking Paris, but not quite. Even though it ultimately failed, it represented the most effective offensive action on the Western Front since the first month of the war. This was immediately followed by the Allies' Hundred Days Offensive that utilized new technologies and better combined arms tactics. Tanks were used to effectively to cross open ground under heavy fire at the Battle of Soisson and the Battle of Amiens. Instead of amassing a huge army in one part of the front and launching a massive artillery bombardment as the British had done at the Somme in 1916 and the French had done at the Chemin Des Dames in 1917, which basically telegraphed to the enemy exactly where and when the large attack would take place, the allies launched a number of smaller attacks up and down the front that were harder to predict. ${ }^{87}$ Similarly

instead of the general interests of all America, would be the only objects of their policy and pursuits. Hence, like most other bordering nations, they would always be either involved in disputes and war, or live in the constant apprehension of them."

Alexander Hamilton, Federalist 6: "A man must be far gone in Utopian speculations, who can seriously doubt that, if these States should either be wholly disunited, or only united in partial confederacies, the subdivisions into which they might be thrown would have frequent and violent contests with each other. To presume a want of motives for such contests, as an argument against their existence, would be to forget that men are ambitious, vindictive, and rapacious. To look for a continuation of harmony between a number of independent, unconnected sovereignties, situated in the same neighborhood, would be to disregard the uniform course of human events, and to set at defiance the accumulated experience of ages." (Hamilton, Madison, and Jay 2008)

87. Australian General John Monash nicely sums up the difference in allied offensive strategy between 1915 and 1918 on the western front: "...the true role of infantry was not to expend itself upon heroic physical 
in early 15th century Europe, the development of siege cannons that fired cast iron balls made previously stout medieval fortifications highly vulnerable and shifted the balance in favor of offense, but the development of the Trace Italienne in the mid to late 15th century by architects such as Francesco di Giorgio Martini and Antonio da Sangallo the Elder, and its subsequent wide adoption, offset this advantage.

Likewise, when offense is strong, militaries innovate so that defense becomes more viable. In Operation Barbarossa in 1941, the Germans launched the largest invasion in history and made strong and fast initial gains, inflicting monthly causalities on the Red Army that are unprecedented in the history of warfare before or since: four million Soviet casualties in the second half of 1941, including three million prisoners captured in pockets in Minsk, Smolensk, Kiev, Bryansk, and Vyazma. By November 1941, the Soviets were already making adjustments that made defense more viable, as they invested heavily in the Mozhaisk defense line around Moscow, which featured a layered defense in depth that was more effective in stopping the German Panzer Armies than forward-deployed armies that had resulted in the previous encirclements. By 1942, the Soviets were more willing to give ground to avoid getting encircled. In the opening stages of the German 1942 Summer offensive, Soviet strategic retreats in the face of the German onslaught avoided giving up prisoners on the scale of the previous year and saved troops for urban fighting in Voronezh and Stalingrad. By 1943 especially, the Soviets had become much better at defensive warfare, as evidenced by their strong defense in depth during the German offensive Operation Citadel in the Kursk salient. ${ }^{88} \mathrm{An}$ important consideration as it relates to the development of better defensive strategy when offense is highly advantaged is that the defender must survive the initial onslaught from the attacker in order to better develop defensive strategy because wars fought under high offensive advantage tend to be quick and decisive. For instance in World War II, the French were defeated so quickly that there was no time for them to adapt and learn in the face of the German tactics. This is in large part because Paris is in the Northeastern part of the country; if the capital had been in Bordeaux, perhaps the French would have been able to adapt fast enough to improve their defensive strategy. By contrast, the space between Bialystok and Moscow is vast, and thus the Soviets were able to repeatedly fail in their defense against the mobile German attack without losing the war; the time and space afforded to them allowed them to adapt their strategy.

Thus, the historical record suggests that there are interesting strategic dynamics

effort, not to wither away under merciless machine-gun fire, not to impale itself on hostile bayonets, nor to tear itself to pieces in hostile entanglements-(I am thinking of Pozières and Stormy Trench and Bullecourt, and other bloody fields) — but on the contrary, to advance under the maximum possible protection of the maximum possible array of mechanical resources, in the form of guns, machine-guns, tanks, mortars and aeroplanes; to advance with as little impediment as possible; to be relieved as far as possible of the obligation to fight their way forward; to march, resolutely, regardless of the din and tumult of battle, to the appointed goal; and there to hold and defend the territory gained; and to gather in the form of prisoners, guns and stores, the fruits of victory."

88. Ziemke and Bauer 1987; Glantz and House 2015. 
between offense and defense. Our analysis shows the implication of a given fixed offense-defense balance, but future work may consider more complex endogenous strategic dynamics, and analyze the effect of these dynamics.

\section{Supplementary Material}

(This is dummy text) Supplementary material for this research note is available at $<$ https://doi.org/10.1017/Sxxxxxxxxx>.

\section{References}

Alesina, Alberto, and Enrico Spolaore. 2005. The Size of Nations. Google-Books-ID: YFo3ByJ10DkC. MIT Press, January 14. ISBN: 978-0-262-26140-1.

Amitai-Preiss, Reuven. 2004. Mongols and Mamluks: The Mamluk-Ilkhanid War, 1260-1281. Cambridge University Press.

Andreski, Stanislav. 1968. Military Organization and Society. Google-Books-ID: chll_LKmN2oC. University of California Press, January 1. ISBN: 978-0-520-00026-1.

Biddle, Stephen. 2001. Rebuilding the Foundations of Offense-Defense Theory. The Journal of Politics 63, no. 3 (August): 741-774. IssN: 0022-3816, 1468-2508. doi:10.1111/00223816.00086. Available at $<$ https://www.journals .uchicago.edu/doi/10.1111/00223816.00086>.

Carlyon, Les. 2002. Gallipoli. Picador Australia.

Cashman, Greg, and Leonard C. Robinson. 2007. An Introduction to the Causes of War: Patterns of Interstate Conflict from World War I to Iraq. Rowman \& Littlefield Publishers, March 1. ISBN: 978-0-7425-5510-5.

Chandler, David G. 2009. The campaigns of Napoleon. Simon / Schuster.

Churchill, Winston. 1987. Memoirs of the Second World War. Houghton Mifflin Harcourt.

Coe, Andrew J. 2011. Costly Peace: A New Rationalist Explanation for War. Unpublished article: 86.

Conlan, Thomas. 2001. In little need of divine intervention: Takezaki Suenaga's scrolls of the Mongol invasions of Japan. Vol. 113. Cornell Univ East Asia Program.

Erenberg, Lewis A. 2019. The Rumble in the Jungle: Muhammad Ali and George Foreman on the Global Stage. Google-Books-ID: i9SWDwAAQBAJ. University of Chicago Press, May 22. ISBN: 978-0-226-05957-0.

Fearon, James D. 1995. THE OFFENSE-DEFENSE BALANCE AND WAR SINCE 1648. Annual meeting of the International Studies Association: 40.

- 2011. Anarchy is a Choice: International Politics \& the Problem of World Government. Columbia University, November 28. Available at $<$ https://www.youtube.com/watch?v= heWczrVE48I>. Accessed July 18, 2018.

2018. Cooperation, Conflict, and the Costs of Anarchy. International Organization 72 (3): 523-559. ISSN: 0020-8183, 1531-5088. doi:10.1017/S0020818318000115. Available at $<$ https://www.cambridge.org/core/product/identifier/S0020818318000115/type/journal_ article $>$. 
Foley, Robert T. 2005. German Strategy and the Path to Verdun: Erich Von Falkenhayn and the Development of Attrition, 1870-1916. Google-Books-ID: sOJ0iRmWGCIC. Cambridge University Press. ISBN: 978-0-521-84193-1.

Garfinkel, Ben, and Allan Dafoe. 2019. How does the offense-defense balance scale? Journal of Strategic Studies 42, no. 6 (September 19): 736-763. ISSN: 0140-2390, 1743-937X. doi:10.1080/01402390.2019.1631810. Available at <https://www.tandfonline.com/doi/full/ 10.1080/01402390.2019.1631810>. Accessed April 29, 2020.

Gartzke, Erik, and Jon R. Lindsay. 2015. Weaving Tangled Webs: Offense, Defense, and Deception in Cyberspace. Security Studies 24, no. 2 (April 3): 316-348. IssN: 0963-6412, 1556-1852. doi:10.1080/09636412.2015.1038188. Available at $<$ http://www.tandfonline. com/doi/full/10.1080/09636412.2015.1038188>. Accessed July 24, 2020.

Gilpin, Robert. 1983. War and change in world politics. Cambridge University Press.

Glantz, David M., and Jonathan M. House. 2015. When Titans Clashed: How the Red Army Stopped Hitler. University Press of Kansas. IsBN: 978-0-7006-2152-1. Available at $<$ https: //muse.jhu.edu/book/42325>. Accessed April 6, 2021.

Glaser, Charles L., and Chaim Kaufmann. 1998. What is the Offense-Defense Balance and Can We Measure it? International Security 22 (4): 44-82. IssN: 0162-2889. doi:10.2307/2539240. Available at $<$ http://www.jstor.org/stable/2539240>.

Hamilton, Alexander, James Madison, and John Jay. 2008. The federalist papers. Oxford University Press.

Hart, Liddell. 1932. Aggression and the Problem of Weapons. The English review, 1908-1937: 71-78.

Hawley, Samuel. 2005. The Imjin War. Transactions of the Korea Branch of the Royal Asiatic Society 78.

- 2014. The Imjin War: Japan's Sixteenth-century Invasion of Korea and Attempt to Conquer China. Google-Books-ID: 4zXsoQEACAAJ. Conquistador Press. ISBN: 978-09920786-2-1.

Hwang, Sung-Ha. 2012. Technology of military conflict, military spending, and war. Journal of Public Economics 96, no. 1 (February): 226-236. Issn: 00472727. doi:10.1016/j. jpubeco.2011.09.003. Available at <https://linkinghub.elsevier.com/retrieve/pii / S0047272711001551>. Accessed May 20, 2020.

Iskandar, A. Z., Unesco, A. Y. Al-Hassan, and Maqbul Ahmed. 2001. The different aspects of Islamic culture: science and technology in Islam. UNESCO Pub.

Jackson, Matthew O. 2009. Strategic Militarization, Deterrence and Wars. Quarterly Journal of Political Science 4, no. 4 (December 30): 279-313. IssN: 15540634. doi:10.1561/100. 00009047. Available at <http://www.nowpublishers.com/article/Details/QJPS-9047>. Accessed July 22, 2019.

Jägermeyr, Jonas, Alan Robock, Joshua Elliott, Christoph Müller, Lili Xia, Nikolay Khabarov, Christian Folberth, et al. 2020. A regional nuclear conflict would compromise global food security. Proceedings of the National Academy of Sciences (March 16): 201919049. IssN: 0027-8424, 1091-6490. doi:10.1073/pnas.1919049117. Available at <http://www.pnas.org/ lookup/doi/10.1073/pnas.1919049117>. Accessed March 21, 2020.

Jervis, Robert. 1978. Cooperation Under the Security Dilemma. World Politics 30 (2): 167-214. ISSN: 0043-8871. doi:10.2307/2009958. Available at <http://www.jstor.org/stable/2009958>.

Jomini, Antoine Henri baron de. 1975. Précis Politique et Militaire des Campagnes de 1812 a 1814. Slatkine-Megariotis Reprints.

Kant, Immanuel. 1983. Perpetual peace and other essays. Hackett Publishing. 
Kydd, Andrew H. 2015. International relations theory. Cambridge University Press.

Levy, Jack S. 1984. The Offensive/Defensive Balance of Military Technology: A Theoretical and Historical Analysis. International Studies Quarterly 28, no. 2 (June): 219. ISSN: 00208833. doi:10.2307/2600696. Available at $<$ https://academic.oup.com/isq/article-lookup/doi/10. 2307/2600696>.

1997. Prospect Theory, Rational Choice, and International Relations. International Studies Quarterly 41, no. 1 (March): 87-112. IssN: 00208833, 14682478. doi:10.1111/00208833.00034. Available at $<$ https://academic.oup.com/isq/article-lookup/doi/10.1111/00208833.00034>.

- 2000. Loss Aversion, Framing Effects, and International. Publisher: University of Michigan Press, Handbook of war studies II: 193.

Lieber, Keir. 2000. Grasping the technological peace: The offense-defense balance and international security. Publisher: MIT Press, International Security 25 (1): 71-104.

- 2014. The offense-defense balance and cyber warfare. Publisher: Naval Postgraduate School Monterey, CA, Cyber analogies: 96-107.

Lines, David A., Marc Laureys, and Jill Kraye. 2015. Forms of Conflict and Rivalries in Renaissance Europe. Google-Books-ID: CTNxCQAAQBAJ. Vandenhoeck \& Ruprecht, May 20. IsBn: 978-3-8470-0409-7.

Lynn-Jones, Sean M. 1995. Offense-defense theory and its critics. Security Studies 4 (4): 660-691.

Mearsheimer, John J. 2001. The tragedy of great power politics. WW Norton \& Company.

Mikaberidze, Alexander. 2016. The Limits of the Operational Art: Russia 1812. Paper presented at the Napoleon and the Operational Art of War, 265-316. Brill.

Moorehead, Alan. 2015. Gallipoli. Aurum Press Limited.

Philpott, William. 2015. War of Attrition: Fighting the First World War. Google-Books-ID: daiMDwAAQBAJ. Abrams, July 21. IsBn: 978-1-4683-1231-7.

Powell, Robert. 1993. Guns, Butter, and Anarchy. American Political Science Review 87, no. 1 (March): 115-132. IsSN: 0003-0554, 1537-5943. doi:10.2307/2938960. Available at $<$ http://www.journals.cambridge.org/abstract_S0003055400099111>. Accessed July 6, 2018.

Quester, George H. 2002. Offense and defense in the international system. Transaction Publishers.

Riehn, Richard K. 1990. 1812: Napoleon's Russian campaign. McGraw-Hill Companies.

Sagan, Scott Douglas. 1995. The limits of safety: Organizations, accidents, and nuclear weapons. Princeton University Press.

Sima, Qian. 1993. Records of the Grand Historian: Qin dynasty. Google-Books-ID: 8SZeT190IA8C. Columbia University Press. ISBN: 978-0-231-08168-9.

Slayton, Rebecca. 2017. What Is the Cyber Offense-Defense Balance? Conceptions, Causes, and Assessment. International Security 41, no. 3 (January): 72-109. IssN: 0162-2889, 1531-4804. doi:10.1162/ISEC_a_00267. Available at <http://www.mitpressjournals.org/doi/10.1162/ ISEC_a_00267>. Accessed July 14, 2018.

Snyder, Jack. 1984. Civil-Military Relations and the Cult of the Offensive, 1914 and 1984. International Security 9 (1): 108. ISSN: 01622889. doi:10.2307/2538637. Available at $<$ https://www.jstor.org/stable/2538637?origin=crossref $>$.

Sondhaus, Lawrence. 2011. World War One: The Global Revolution. Google-Books-ID: EU5gAgAAQBAJ. Cambridge University Press, March 31. IsBn: 978-1-107-78250-1.

Stavros, Matthew. 2013. Military Revolution in Early Modern Japan. Japanese Studies 33, no. 3 (December): 243-261. ISsN: 1037-1397, 1469-9338. doi:10.1080/10371397.2013.831733. 
Available at <http://www.tandfonline.com/doi/abs/10.1080/10371397.2013.831733>. Accessed July 23, 2020.

Taylor, Alan John Percivale. 1963. Illustrated History of the First World War. Putnam.

Tooze, Adam. 2008. The Wages of Destruction: The Making and Breaking of the Nazi Economy.

Penguin, February 26. IsBN: 978-1-101-56495-0.

Tschanz, David W. 2007. History's Hinge: Ain Jalut. Publisher: ARAMCO SERVICES COMPANY, Saudi Aramco World 58 (4): 24.

Tzu, Sun. 2008. The art of war. Paper presented at the Strategic Studies, 63-91. Routledge.

Van Evera, Stephen. 1984. The Cult of the Offensive and the Origins of the First World War. International Security 9 (1): 58. ISSN: 01622889. doi:10.2307/2538636. Available at $<$ https://www.jstor.org/stable/2538636?origin=crossref $>$.

. 1998. Offense, Defense, and the Causes of War. International Security 22 (4): 5. ISSN: 01622889. doi:10.2307/2539239. Available at <https://www.jstor.org/stable/2539239? origin $=$ crossref $>$.

Waltz, Kenneth N. 1981. The Spread of Nuclear Weapons: More May Be Better: Introduction. Watson, Alexander. 2014. Ring of Steel: Germany and Austria-Hungary in World War I. Google-Books-ID: jGboBAAAQBAJ. Basic Books, October 7. IsBN: 978-0-465-05687-3.

Wink, André. 1991. Al-Hind the Making of the Indo-Islamic World: The Slave Kings and the Islamic Conquest : 11Th-13th Centuries. Google-Books-ID: 75FlxDhZWpwC. BRILL. IsBn: 978-90-04-10236-1.

Zaloga, Steven J. 2014. French Tanks of World War II (2): Cavalry Tanks and AFVs. Bloomsbury Publishing.

Ziemke, Earl F., and Magna E. Bauer. 1987. Moscow to Stalingrad: decision in the east. 12. Center of Military History, United States Army.

\section{Appendix}

\section{Formal Assumptions about the Contest Success Function}

The Contest Success Function (CSF) determines the probability that one side defeats the other side in a dyadic contest. $p^{i}\left(a_{i}, a_{j} ; m\right) \in[0,1]$ is the probability that player $i$ defeats player $\mathrm{j}$ in the contest. In some cases we will specify whether the CSF applies to whether the player is attacking or defending. $p_{o}^{i}\left(a_{i}, a_{j} ; m\right) \in[0,1]$ is the probability that $\mathrm{i}$ wins when they attack $\mathrm{j} . p_{d}^{i}\left(a_{i}, a_{j} ; m\right) \in[0,1]$ is the probability that $\mathrm{i}$ wins when they are being attacked by j. $p_{s}^{i}\left(a_{i}, a_{j} ; m\right) \in[0,1]$ is the probability that $i$ wins when $i$ and $j$ simultaneously attack. We make the following assumptions about the contest success function:

1. $p^{i}\left(a_{i}, a_{j} ; m\right)$ is continuous and differentiable

2. $p^{i}\left(a_{i}, a_{j} ; m\right)$ is symmetric across players with the same parameter values. For a given player 1 and 2: $p_{o}^{1}(a, b ; m)=p_{o}^{2}(a, b ; m), p_{d}^{1}(a, b ; m)=p_{d}^{2}(a, b ; m)$, $p_{s}^{1}(a, b ; m)=p_{s}^{2}(a, b ; m)$

3. An unarmed state will be defeated with $100 \%$ certainty in any war against a state with any positive amount of arms: $\lim _{a_{j} \rightarrow 0} p^{i}\left(a_{i}, a_{j} ; m\right)=1$ for $a_{i}>0$.

4. The more arms player $i$ has, the greater chance they have of winning the contest: $\frac{\partial p^{i}\left(a_{i}, a_{j} ; m\right)}{\partial a_{i}}>0$ 
5. There are diminishing marginal returns to arms: $\frac{\partial p^{i}\left(a_{i}, a_{j} ; m\right)}{\partial^{2} a_{i}}<0$

6. The attacker's probability of winning is increasing in offensive advantage $\frac{\partial p_{o}^{i}\left(a_{i}, a_{j} ; m\right)}{\partial m}>0$. In addition, $\lim _{m \rightarrow 0} p_{o}^{i}\left(a_{i}, a_{j} ; m\right)=0$ and $\lim _{m \rightarrow \infty} p_{o}^{i}\left(a_{i}, a_{j} ; m\right)=$ 1 provided that the attacker spends some $a>0$ on arms

7. The defender's probability of winning is decreasing in offensive advantage $\frac{\partial p_{d}^{i}\left(a_{i}, a_{j} ; m\right)}{\partial m}<0$. In addition, $\lim _{m \rightarrow 0} p_{d}^{i}\left(a_{i}, a_{j} ; m\right)=1$ and $\lim _{m \rightarrow \infty} p_{d}^{i}\left(a_{i}, a_{j} ; m\right)=$ 0 provided that the spender spends some $a>0$ on arms

8. One side must win and one side must lose: $p^{i}\left(a_{i}, a_{j} ; m\right)+p^{j}\left(a_{j}, a_{i} ; m\right)=1$

9. $m>1$ implies offensive advantage, i.e. for fixed arms levels $\left(a_{i}, a_{j}\right)$, attacking yields a higher probability of success than simultaneous attack, which yields a higher probability of success than defending: $p_{o}^{i}\left(a_{i}, a_{j} ; m\right)>p_{s}^{i}\left(a_{i}, a_{j} ; m\right)>$ $p_{d}^{i}\left(a_{i}, a_{j} ; m\right)$

10. $m=1$ implies offensive-defense neutrality, i.e. for fixed arms levels $\left(a_{i}, a_{j}\right)$, attacking, defending, and simultaneous attack all yield the same probability of success: $p_{o}^{i}\left(a_{i}, a_{j} ; m\right)=p_{s}^{i}\left(a_{i}, a_{j} ; m\right)=p_{d}^{i}\left(a_{i}, a_{j} ; m\right)$

11. $m<1$ implies defensive advantage, i.e. for fixed arms levels $\left(a_{i}, a_{j}\right)$, defending yields a higher probability of success than simultaneous attack, which yields a higher probability of success than attacking: $p_{d}^{i}\left(a_{i}, a_{j} ; m\right)>p_{s}^{i}\left(a_{i}, a_{j} ; m\right)>$ $p_{o}^{i}\left(a_{i}, a_{j} ; m\right)$

\section{Solving for Equilibrium Arms Levels and Welfare in the Dynamic Model with Endogenous Arming and Exogenous War Costs}

Our extension to the (Fearon 2018) model requires us to model war equilibria in addition to the peace equilibria analyzed by Fearon. In addition, we allow states to have a discount rate bounded away from zero, which implies that states will not necessarily fully arm in war equilibria.

Below, we find analytical solutions for equilibrium arms levels and states' expected utilities in war equilibria using the Karush-Kuhn-Tucker (KKT) conditions for constrained optimization. This allows us to run comparative comparative statics on the equilibria, which are useful for proving our propositions related to our Welfare is U-Shaped Under Offensive Advantage (WUO) hypothesis.

As discussed in the main text, depending on the offense defense balance, there are some pure strategy war equilibria when one side attacks and one side defends (when $m<1$ ) and there are some where both sides simultaneously attack (when $m>1)$.

We thus take the following steps, which are divided into subsections below:

- We solve for the best response arms levels and expected utility for a state that attacks another defending state as a function of the other state's arms levels

- We solve for the best response arms levels and expected utility for a state that is defending against another state's attack as a function of the other state's 
arms levels

- We solve for the reduced form Nash Equilibrium arms levels in the attackdefend equilibrium (where one state is attacking, and one is defending)

- We run comparative statics in the attack-defend war equilibrium to determine how welfare evolves under changes in the offense-defense balance

- We solve for the best response arms levels and expected utility for a state that attacks another state while that state is also simultaneously attacking it as a function of the other state's arms levels

- We solve for the reduced form Nash Equilibrium arms levels in the simultaneous attack war equilibrium

- We run comparative statics in the simultaneous attack war equilibrium to determine how welfare evolves under changes in the offense-defense balance

\section{Arms Levels and Expected Utility Under Attack}

We can solve analytically for the RHS of equation 3 (the dynamic war constraint) using the Karush-Kuhn-Tucker (KKT) conditions for constrained optimization. We can see that this maximization problem meets the KKT conditions:

(a) By assumption, $p^{i}(a, \hat{a} ; m)$ is increasing and concave in $a$ (this follows from CSF assumptions 4 and 5 stipulated above). Therefore the objective function is weakly concave. The objective function is also continuous and differentiable.

(b) The choice variable $a \in[0,1]$ is drawn from a compact set.

Now we can draw up our Lagrangian and first order conditions:

$$
\left.L=1-a+p^{i}(a, \hat{a} ; m)\right) \phi+\lambda a+\theta(1-a)
$$

Where $\phi=\frac{[\gamma-c+\delta(1+\mu)]}{(1-\delta)}$, i.e. the perpetuity benefit from winning the war.

Not that the suggested functional form for the attack contest success function is:

$$
p_{o}^{i}\left(a_{i}, a_{j} ; m\right)=\frac{m a_{i}}{m a_{i}+a_{j}}
$$

And note that:

$$
\frac{\partial p_{o}^{i}\left(a_{i}, a_{j} ; m\right)}{\partial a_{i}}=\frac{m a_{j}}{\left(m a_{i}+a_{j}\right)^{2}}
$$

\section{Case 1: Interior Solution (Partial Arming)}

Start by assuming an interior solution (both complementary slackness conditions bind) and finding the first order condition of the Lagrangian, it follows that:

$$
\frac{\partial p^{i}(a, \hat{a} ; m)}{\partial a} \phi=1
$$


Where the LHS represents the marginal benefit of arming: the marginal increase in the probability of winning the war multiplied by the perpetuity benefit of war. The RHS is the marginal cost of arming.

We can then use this functional form to solve for arms levels in equilibrium when there is an interior solution:

$$
a=\sqrt{\frac{\hat{a} \phi}{m}}-\frac{\hat{a}}{m}
$$

Recall that the expected utility of war is:

$$
E U_{i}(w a r)=1-a_{i}+p_{i}\left(a_{i}, a_{j} ; m\right) \phi
$$

We can then plug in equations A1 and A4 to solve for the expected utility of attacking. Simplifying yields the following expression:

$$
E U_{i}(\text { attack })=1+\frac{\hat{a}}{m}+\phi-2 \sqrt{\frac{\hat{a} \phi}{m}}
$$

\section{Case 2: Full Arming}

When there is full arming $(a=1)$, the FOC becomes:

$$
\frac{\partial p^{i}(a, \hat{a} ; m)}{\partial a} \phi-\theta=1
$$

For the Lagrange multiplier $\theta>0$, which represents the shadow price of increasing arms beyond the level where $a=1$. This implies that the marginal benefit of arming at $a=1$ is greater than the marginal cost of arming:

$$
\left.\frac{\partial p^{i}(a, \hat{a} ; m)}{\partial a} \phi\right|_{a=1}>1
$$

Plugging in the preferred functional form for the contest success function, we find that this occurs when:

$$
\phi>\frac{(m+\hat{a})^{2}}{(m+\hat{a}) m-m^{2}}
$$

Which simplifies to:

$$
\phi>\frac{(m+\hat{a})^{2}}{m \hat{a}}
$$

In this case the expected value of attacking is:

$$
E U_{i}(w a r)=\frac{\phi}{1+\frac{\hat{a}}{m}}
$$




\section{Case 3: No Arming}

When there is no arming $(a=0)$, the FOC becomes:

$$
\frac{\partial p^{i}(a, \hat{a} ; m)}{\partial a} \phi+\lambda=1
$$

For the Lagrange multiplier $\lambda>0$, which represents the shadow price of relaxing the constraint where the players can spend no less on arms than $a=0$. This implies that the marginal benefit of arming at $a=0$ is less than the marginal cost of arming:

$$
\frac{\partial p^{i}(a, \hat{a} ; m)}{\partial a} \phi||_{a=0}<1
$$

Plugging in the preferred functional form of the contest success function, we find that this occurs when:

$$
\phi<\frac{\hat{a}}{m}
$$

By the assumptions we made for the war CSF, an unarmed state loses with $100 \%$ certainty, so the expected value of war is:

$$
E U_{i}(\text { war })=1-0+0 * \phi
$$

Which simplifies to::

$$
E U_{i}(\text { war })=1
$$

\section{Summary}

We can summarize the results in figure A1 
FIGURE A1.

\section{Optimal Arms Levels Under Attack}

As a function of the other sides' arms levels $\hat{a}$

Occurs When

No Arming

$a=0$
Arms Levels

$a=0$
$\boldsymbol{E U}_{\boldsymbol{i}}(\boldsymbol{a t t a c k})$

1
Partial Arming
$a \in(0,1)$
$\frac{\hat{a}}{m}<\phi<\frac{(m+\hat{a})^{2}}{m \hat{a}}$
$a=\sqrt{\frac{\hat{a} \phi}{m}}-\frac{\hat{a}}{m}$
$1+\frac{\hat{a}}{m}+\phi-2 \sqrt{\frac{\hat{a} \phi}{m}}$

Full Arming

$a=1$

$\phi \geq \frac{m}{\hat{a}}+2+\frac{\hat{a}}{m}=\frac{(m+\hat{a})^{2}}{m \hat{a}} \quad a=1$

$\frac{1}{1+\frac{\hat{a}}{m}} \phi$

\section{Arms Levels and Welfare Under Defense}

When the war constraint is not satisfied and defense is advantaged (scenario 2: Rope-a-Dope) there are two anti-coordination equilibria and one mixed strategy equilibrium. Consistent with the rest of the analysis, we will focus on the pure strategy equilibria.

To find arms levels and welfare in this scenario, we will consider the situation in which one side maximizes their arms levels for defense and the other side maximizes their arms levels for attack.

We already found optimal arms levels under attack in section 11 , so now we will need to solve analytically for optimal arms levels under defense as a function of the other sides' arms using the Karush-Kuhn-Tucker (KKT) conditions for constrained optimization as we did in section 11 .

The results of this optimization are shown in figure $\mathrm{A} 2$. 


\section{Optimal Arms Levels Under Defense}

As a function of the other sides' arms levels

\begin{tabular}{|c|c|c|c|}
\hline & Occurs When & Arms Levels & $E U_{i}($ defend $)$ \\
\hline $\begin{array}{c}\text { No Arming } \\
a_{i}=0\end{array}$ & $\phi \leq m a_{j}$ & $a_{i}=0$ & 1 \\
\hline $\begin{array}{c}\text { Partial Arming } \\
a_{i} \in(0,1)\end{array}$ & $m a_{j}<\phi<\frac{\left(m a_{j}+1\right)^{2}}{m a_{j}}$ & $a_{i}=\sqrt{m a_{j} \phi-m a_{j}}$ & $1+\phi+m a_{j}-2 \sqrt{m a_{j} \phi}$ \\
\hline $\begin{array}{l}\text { Full Arming } \\
\qquad a_{i}=1\end{array}$ & $\phi \geq \frac{\left(m a_{j}+1\right)^{2}}{m a_{j}}$ & $a_{i}=1$ & $\frac{\phi}{m a_{j}+1}$ \\
\hline
\end{tabular}

Below is the derivation for figure A2 Assume that player i is defending against player $\mathrm{j}$ 's attack. The contest success function for player $\mathrm{i}$ is:

$$
p_{d}^{i}\left(a_{i}, a_{j} ; m\right)=\frac{a_{i}}{a_{i}+m a_{j}}
$$

Note that the partial derivative with respect to $a_{i}$ is:

$$
\frac{\partial p_{d}^{i}}{\partial a_{i}}=\frac{m a_{j}}{\left(a_{i}+m a_{j}\right)^{2}}
$$

We use the same Lagrangian as in section 11, but with the contest success function described above. We will skip the Lagrangian steps for the general contest success function (see 11 for those steps) and skip right to the steps where we plug in the defender's contest success function to solve for their optimal arms levels and expected utility.

\section{Case 1: Interior Solution (Partial Arming)}

From 11 , we find that in the partial arming $\left(0<a_{i}<1\right)$ scenario:

$$
\frac{\partial p_{i}}{\partial a_{i}} \phi=1
$$

Plugging in the defender's CSF: 


$$
\frac{m a_{j}}{\left(a_{i}+m a_{j}\right)^{2}} \phi=1
$$

Solving for arms levels:

$$
a_{i}=\sqrt{m a_{j} \phi}-m a_{j}
$$

And plugging in arms levels to the equation for expected utility under war (equation A5, expected utility is:

$$
E U_{i}(\text { defend })=1-\sqrt{m a_{j} \phi}+m a_{j}+\frac{\sqrt{m a_{j} \phi}-m a_{j}}{m a_{j}+\sqrt{m a_{j} \phi}-m a_{j}} \phi
$$

Simplifying, we get:

$$
E U_{i}(\text { defend })=1+\phi+m a_{j}-2 \sqrt{m a_{j} \phi}
$$

\section{Case 2: Full Arming}

From 11 , we find that in the full arming $\left(a_{i}=1\right)$ scenario:

$$
\left.\frac{\partial p_{i}}{\partial a_{i}}\right|_{a_{i}=1} \geq 1
$$

Plugging in equation $\mathrm{A} 12$

$$
\frac{m a_{j}}{\left(1+m a_{j}\right)^{2}} \phi \geq 1
$$

This leads to the condition:

$$
\phi \geq \frac{\left(m a_{j}+1\right)^{2}}{m a_{j}}
$$

Plugging in $a_{i}=1$ into equation $\mathrm{A} 5$ the expected value is:

$$
E U_{i}(\text { defend })=\frac{\phi}{m a_{j}+1}
$$

\section{Case 3: No Arming}

From 11 , we find that in the no arming $\left(a_{i}=0\right)$ scenario:

$$
\left.\frac{\partial p_{i}}{\partial a_{i}}\right|_{a_{i}=0} \leq 1
$$

Plugging in equation $\mathrm{A} 12$. 


$$
\frac{\phi}{m a_{j}} \phi \leq 1
$$

This leads to the condition:

$$
\phi \leq m a_{j}
$$

And the expected value is:

$$
E U_{i}=1
$$

\section{Reduced Form Nash Equilibrium in Attack-Defend Dyad}

Now that we've solved for optimal arms levels under both attack and defend as a function of the other side's arms levels, we can plug in these solutions to find the Nash Equilibrium reduced form arms levels and expected utility for the attack-defend dyad in figure A3, and the derivation is shown below.:

FIGURE A3

\begin{tabular}{|c|c|c|c|}
\hline & Arms Levels & Individual Expected Utility & $\begin{array}{l}\text { Total Expected Utility } \\
\quad\left(E U_{o}+E U_{d}\right)\end{array}$ \\
\hline$\underset{\phi \leq 0}{\text { No arming }}$ & $a_{o, d}=0$ & $E U_{o}=1+\frac{\gamma}{2} ; E U_{d}=1+\frac{\gamma}{2}$ & $2+\gamma$ \\
\hline $\begin{array}{l}\text { Full Arming } \\
\qquad \phi \geq \frac{(m+1)^{2}}{m}\end{array}$ & $a_{o, d}=1$ & $E U_{o}=\frac{\phi}{1+\frac{1}{m}} ; E U_{d}=\frac{\phi}{m+1}$ & $\phi$ \\
\hline $\begin{array}{c}\text { Partial } \\
\text { Arming } \\
0<\phi<\frac{(m+1)^{2}}{m}\end{array}$ & $a_{o, d}=\frac{m \phi}{(1+m)^{2}}$ & $\begin{array}{l}E U_{o}=1+\frac{m^{2} \phi}{(1+m)^{2}} \\
E U_{d}=1+\frac{\phi}{(1+m)^{2}}\end{array}$ & $2+\frac{\phi\left(m^{2}+1\right)}{(1+m)^{2}}$ \\
\hline
\end{tabular}

\section{Nash Equilibrium Reduced Form Arms Levels and Expected Utility under Attack-Defend Dyad}

Start by assuming that player o (attacker) attacks player d (defender). We already solved for the attacker's arms levels as a function of the defender's arms levels and the defender's arms levels as a function of the attacker's arms levels. Now we 
can combine these results to find the Nash equilibrium such that both players are playing best responses to the strategy of the other side.

\section{Case 1: Full Arming}

Is there an equilibrium where one side partially arms while the other is fully arming? Let's begin by considering the case where the attacker is fully arming, and see if there is an equilibrium in which the defender is partially arming.

Assume that the defender chooses arms such that:

$$
\phi \geq \frac{\left(m+a_{d}\right)^{2}}{m a_{d}}
$$

Recall that in this case, the attacker's best response is to choose arms levels $a_{o}=1$.

Now consider the defender's best response. Recall that full arming is the defender's best response if:

$$
\phi \geq \frac{\left(m a_{o}+1\right)^{2}}{m a_{o}}
$$

Since $a_{o}=1$ by assumption, then:

$$
\phi \geq \frac{(m+1)^{2}}{m}
$$

Therefore, for the defender to partially arm, it must be the case that:

$$
\frac{(m+1)^{2}}{m}>\phi
$$

So now we have two conditions (A22) and A20 that must hold for the attacker to fully arm and for the defender to partially arm.

Recall that when the defender is partially arming, their best response arms levels are determined by:

$$
a_{d}=\sqrt{m a_{o} \phi}-m a_{o}
$$

Plugging this into equation A22:

$$
\phi \geq \frac{\left(m+\sqrt{m a_{o} \phi}-m a_{o}\right)^{2}}{\sqrt{m a_{o} \phi}-m a_{o}}
$$

Because $a_{o}=1$ by assumption:

$$
\phi \geq \frac{(m+\sqrt{m \phi}-m)^{2}}{\sqrt{m \phi}-m a_{o}}
$$


Simplifying, we get the condition:

$$
\phi \geq \frac{(m+1)^{2}}{m}
$$

However, this condition is the complement of A20 and it is impossible to satisfy both conditions. Therefore, there is no equilibrium in which the attacker fully arms, but the defender partially arms.

Now we consider the case where the defender is fully arming, and check to so if there is an equilibrium in which the attacker partially arms.

Assume that the attacker chooses arms such that:

$$
\phi \geq \frac{\left(m a_{o}+1\right)^{2}}{m a_{o}}
$$

Recall that the defender's best response under this condition is to choose arms such that $a_{d}=1$.

Now consider the attacker's best response. Recall that full arming is the attacker's best response if:

$$
\phi \geq \frac{\left(m+a_{d}\right)^{2}}{m a_{d}}
$$

Because $a_{d}=1$ by assumption, then:

$$
\phi \geq \frac{(m+1)^{2}}{m}
$$

Therefore, for the attacker to partially arm, it must be the case that:

$$
\frac{(m+1)^{2}}{m}>\phi
$$

Now, we have two conditions (A22) and (A23) that must hold for the defender to fully arm and for the attacker to partially arm.

Recall that when the attacker's best response under partial arming is given by:

$$
a_{o}=\sqrt{\frac{a_{d} \phi}{m}}-\frac{a_{d}}{m}
$$

Because $a_{d}=1$ by assumption, then:

$$
a_{o}=\sqrt{\frac{\phi}{m}}-\frac{1}{m}
$$

Plugging this into equation A22):

$$
\phi \geq \frac{\left[m\left(\sqrt{\frac{\phi}{m}}-\frac{1}{m}\right)+1\right]^{2}}{m\left(\sqrt{\frac{\phi}{m}}-\frac{1}{m}\right)}
$$


Simplifying, we get:

$$
\phi \geq \frac{(m+1)^{2}}{m}
$$

However, this condition is the complement of A23 and it is impossible to satisfy both conditions. Therefore, there is not an equilibrium in which the defender fully arms, but the attacker partially arms.

We have now proved that there is no condition where one side fully arms while the either side partially arms. The only equilibrium with full arming involves both sides fully arming.

When both states fully arm:

$$
\begin{gathered}
E U_{o}=\frac{\phi}{1-1 / m} \\
E U_{d}=\frac{\phi}{m+1} \\
E U_{\text {total }}=\phi
\end{gathered}
$$

\section{Case 2: No arming, no war}

Consider the case where:

$$
\phi \leq 0
$$

In this case there is never any war because the expected value from winning a war when spending nothing on arms in negative. In this case, states will spend nothing on arms.

$$
\begin{gathered}
E U_{o}=1+\frac{\gamma}{2} \\
E U_{d}=1+\frac{\gamma}{2} \\
E U_{\text {total }}=2+\gamma
\end{gathered}
$$

\section{Case 3: Partial Arming}

Recall that under the partial arming condition, the attacker's best response arms levels are:

$$
a_{o}=\sqrt{\frac{a_{d} \phi}{m}}-\frac{a_{d}}{m}
$$


Recall that under partial arming, the defender's best response arms levels are:

$$
a_{d}=\sqrt{m a_{o} \phi}-m a_{o}
$$

We can then plug equation A32 into equation A31 to solve for $a_{o}$ as a function of exogenous variables.

After a good deal of algebra shown in figure ??, we find:

$$
a_{o}=\frac{m \phi}{(1+m)^{2}}
$$

We can then plug equation A33 into equation A32. After a good deal of algebra shown in figure ??, we find that defender's will invest the same amount in their arms under partial arming:

$$
a_{d}=\frac{m \phi}{(1+m)^{2}}
$$

Now that we solved for $a_{o}$ and $a_{d}$ as a function of exogenous variables, we can plug these into equation A5 to find expected utility for the attacker and defender as a function of exogenous variables. After a good deal of algebra shown in figure ??, we find that expected utility for the attacker is:

$$
E U_{o}=1+\frac{m^{2} \phi}{(1+m)^{2}}
$$

After a good deal of algebra shown in figure ??, we find that expected utility for the defender is:

$$
E U_{d}=1+\frac{\phi}{(1+m)^{2}}
$$

The total utility under partial arming in the attack-defend dyad is:

$$
E U_{\text {total }}=2+\frac{\phi\left(m^{2}+1\right)}{(1+m)^{2}}
$$

\section{Comparative Statics}

Importantly, because we now have a reduced-form solution for total welfare (i.e. total expected utility) in figure A3, we can do comparative statics to see how welfare in the attack-defend dyad changes with the offense-defense balance.

As expected, expected utility for the attacker is strictly increasing in offensive advantage:

$$
\frac{\partial E U_{o}}{\partial m}=\frac{2 m \phi}{(1+m)^{3}}
$$


As expected, expected utility for the defender is strictly decreasing in offensive advantage:

$$
\frac{\partial E U_{d}}{\partial m}=\frac{-2 \phi}{(1+m)^{3}}
$$

Total expected utility is decreasing in $\mathrm{m}$ when $m<1$, but increasing in $\mathrm{m}$ when $m>1$ :

$$
\frac{\partial E U_{\text {total }}}{\partial m}=\frac{2 \phi(m-1)}{(1+m)^{3}}
$$

The driver of the U-shape of total expected utility under offensive advantage is the equilibrium arms levels. Under partial arming, arms levels for both the attacker and defender are increasing when $m<1$, which decreases total welfare. They are increasing when $m>1$, which increases total welfare:

$$
\frac{\partial\left(a_{o}=a_{d}\right)}{\partial m}=\frac{\phi(1-m)}{(1+m)^{3}}
$$

The full chart that shows comparative statics of welfare under expected utility in the attack-defend Dyad is shown below. A dynamic Mathematica file of this chart is included in the supplementary materials. 
FIGURE A4. Welfare Under Offensive Advantage in the Attack-Defend Dyad
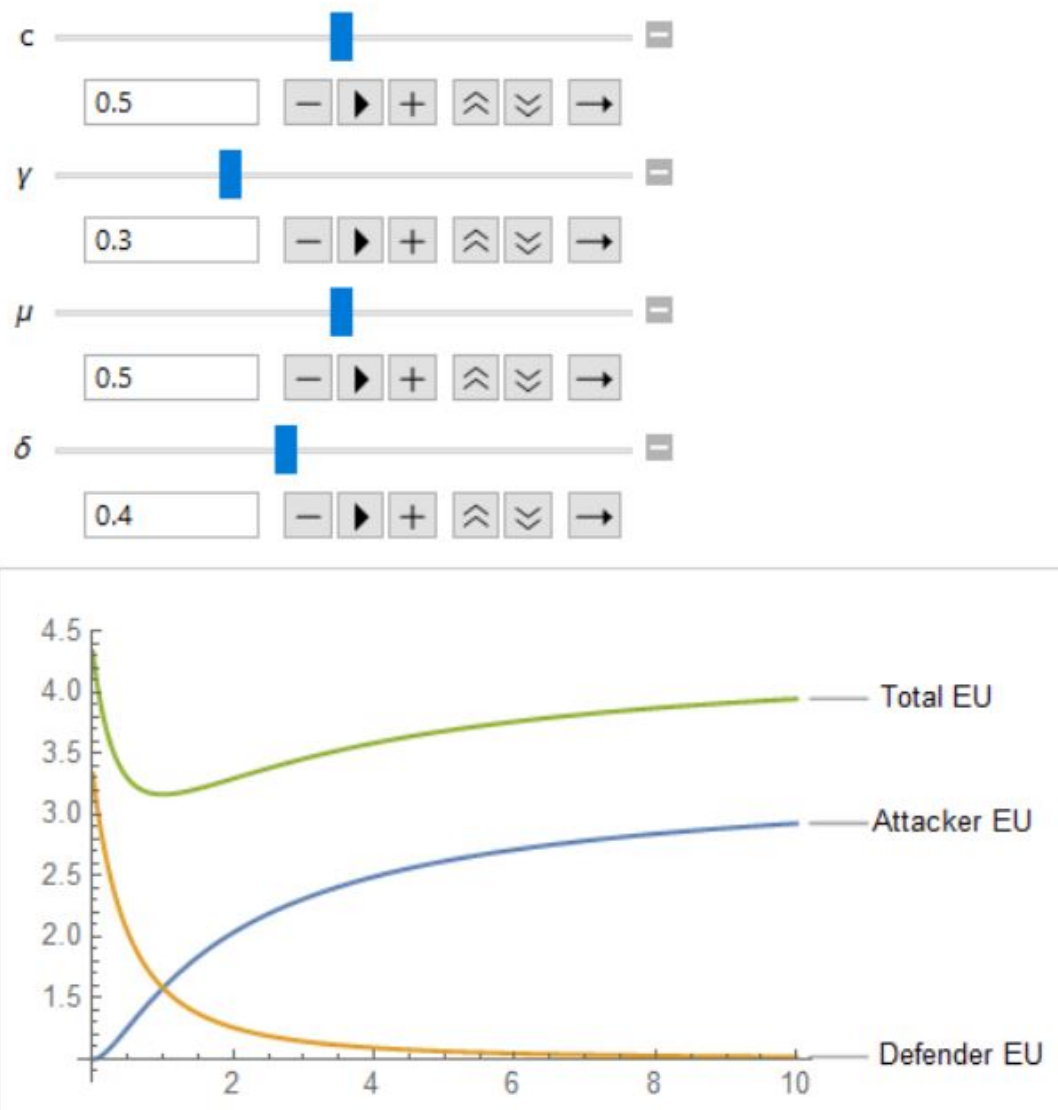

Arms Levels and Welfare Under Simultaneous Attack

Under simultaneous attack, we assume a "coin flip" CSF, i.e. there is a $50 \%$ chance that a given side ends up on the attack and a 50\% chance they end up on the defense. Formally:

$$
p_{s}^{i}\left(a_{i}, a_{j} ; m\right)=\left(\frac{1}{2}\right)\left(\frac{m a_{i}}{a_{i}+m a_{j}}\right)+\left(\frac{1}{2}\right)\left(\frac{a_{i}}{m a_{i}+a_{j}}\right)
$$


And note that:

$$
\frac{\partial p_{s}^{i}\left(a_{i}, a_{j} ; m\right)}{\partial a_{i}}=\left(\frac{1}{2}\right)\left(\frac{m a_{j}}{\left(m a_{i}+a_{j}\right)^{2}}\right)+\left(\frac{1}{2}\right)\left(\frac{m a_{j}}{\left(a_{i}+m a_{j}\right)^{2}}\right)
$$

\section{Partial Arming}

Recall the general Karush Kuhn Tucker conditions for the choice of arms levels in the war scenarios.

Under an interior solution:

$$
\frac{\partial p^{i}\left(a_{i}, a_{j} ; m\right)}{\partial a_{i}} \phi=1
$$

Where the LHS represents the marginal benefit of arming: the marginal increase in the probability of winning the war multiplied by the perpetuity benefit of war. The RHS is the marginal cost of arming.

In the attack-defend dyad, the attacker and the defender had different CSFs. However, in the simultaneous attack dyad, the CSFs of both sides have the same functional form, and we can use this to our advantage. Because $\phi$ is identical for both players by assumption, we end up with the condition:

$$
\frac{\partial p^{i}\left(a_{i}, a_{j} ; m\right)}{\partial a_{i}}=\frac{\partial p^{j}\left(a_{j}, a_{i} ; m\right)}{\partial a_{j}}=\frac{1}{\phi}
$$

Plugging in the functional form for the CSF:

$$
\left(\frac{1}{2}\right)\left[\frac{m a_{j}}{\left(m a_{i}+a_{j}\right)^{2}}+\frac{m a_{j}}{\left(a_{i}+m a_{j}\right)^{2}}\right]=\left(\frac{1}{2}\right)\left[\frac{m a_{i}}{\left(m a_{j}+a_{i}\right)^{2}}+\frac{m a_{i}}{\left(a_{j}+m a_{i}\right)^{2}}\right]=\frac{1}{\phi}
$$

We can see that this equation is solved when both sides arm equally, i.e. $a_{i}=a_{j}$. We will call this arms level $a$. When we plug in a single arms levels $a$, we get the following condition:

$$
\frac{m a}{(a+a m)^{2}}+\frac{m a}{(a+a m)^{2}}=\frac{2}{\phi}
$$

Simplifying and solving for a:

$$
a=\frac{m \phi}{(m+1)^{2}}
$$

Plugging this reduced-form solution for arms into the expression for expected utility in war, $E U_{i}(w a r)=1-a_{i}+p_{i}\left(a_{i}, a_{j} ; m\right) \phi$ yields:

$$
E U_{i}(\text { simultaneous })=\frac{2+\phi}{2}-\frac{m \phi}{(m+1)^{2}}
$$




\section{Full Arming}

In a corner solution with full arming, recall the general Karush Kuhn Tucker condition:

$$
\frac{\left.\partial p^{i}\left(a_{i}, a_{j}\right) ; m\right)}{\partial a_{i}} \phi-\theta=1
$$

For the Lagrange multiplier $\theta>0$, which represents the shadow price of increasing arms beyond the level where $a=1$. This implies that the marginal benefit of arming at $a=1$ is greater than the marginal cost of arming:

$$
\frac{\partial p^{i}\left(a_{i}, a_{j} ; m\right)}{\partial a_{i}} \phi||_{a_{i}=1} \geq 1
$$

Because both players have identical CSF functional forms and $\phi$ values, the threshold for where full arming occurs is equal for both players:

$$
\left.\frac{\partial p^{i}\left(a_{i}, a_{j} ; m\right)}{\partial a_{i}}\right|_{a_{i}=1}=\left.\frac{\partial p^{j}\left(a_{j}, a_{i} ; m\right)}{\partial a_{j}}\right|_{a_{j}=1}=\frac{1}{\phi}
$$

Plugging in functional forms:

$$
\left(\frac{1}{2}\right)\left[\frac{m a_{j}}{\left(m+a_{j}\right)^{2}}+\frac{m a_{j}}{\left(1+m a_{j}\right)^{2}}\right]=\left(\frac{1}{2}\right)\left[\frac{m a_{i}}{\left(m+a_{i}\right)^{2}}+\frac{m a_{i}}{\left(1+m a_{i}\right)^{2}}\right]=\frac{1}{\phi}
$$

We can see that this equation is solved when $a_{j}=a_{i}$. Since we assumed that $a_{i}=1$ and $a_{j}=1$, we can plug in this into the full arming condition with the functional form:

$$
\left(\frac{1}{2}\right)\left[\frac{m}{(m+1)^{2}}+\frac{m}{(1+m)^{2}}\right] \geq \frac{1}{\phi}
$$

Simplifying, we get the condition that full arming occurs when:

$$
\phi \geq 2(m+1)
$$

And the expected utility under this condition is:

$$
E U_{i}(\text { simultaneous })=\frac{\phi}{2}
$$

\section{No Arming}

And recall that when the perpetuity benefit of winning the war is negative, $\phi \leq 0$, then neither side will arm and there will be peace.

\section{Reduced Form Nash Equilibrium in Simultaneous Attack Dyad}


FIGURE A5

\section{Nash Equilibrium Reduced Form Arms Levels and Expected Utility under Simultaneous Attack Dyad}

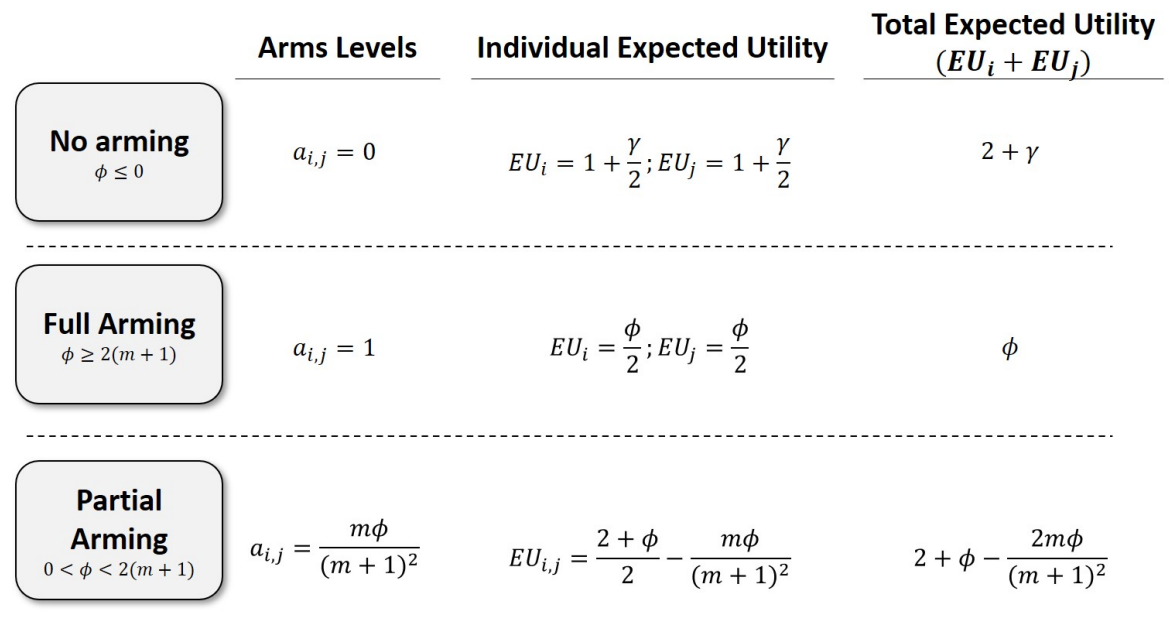


FIGURE A6. Welfare Under Offensive Advantage in the Simultaneous Attack Dyad
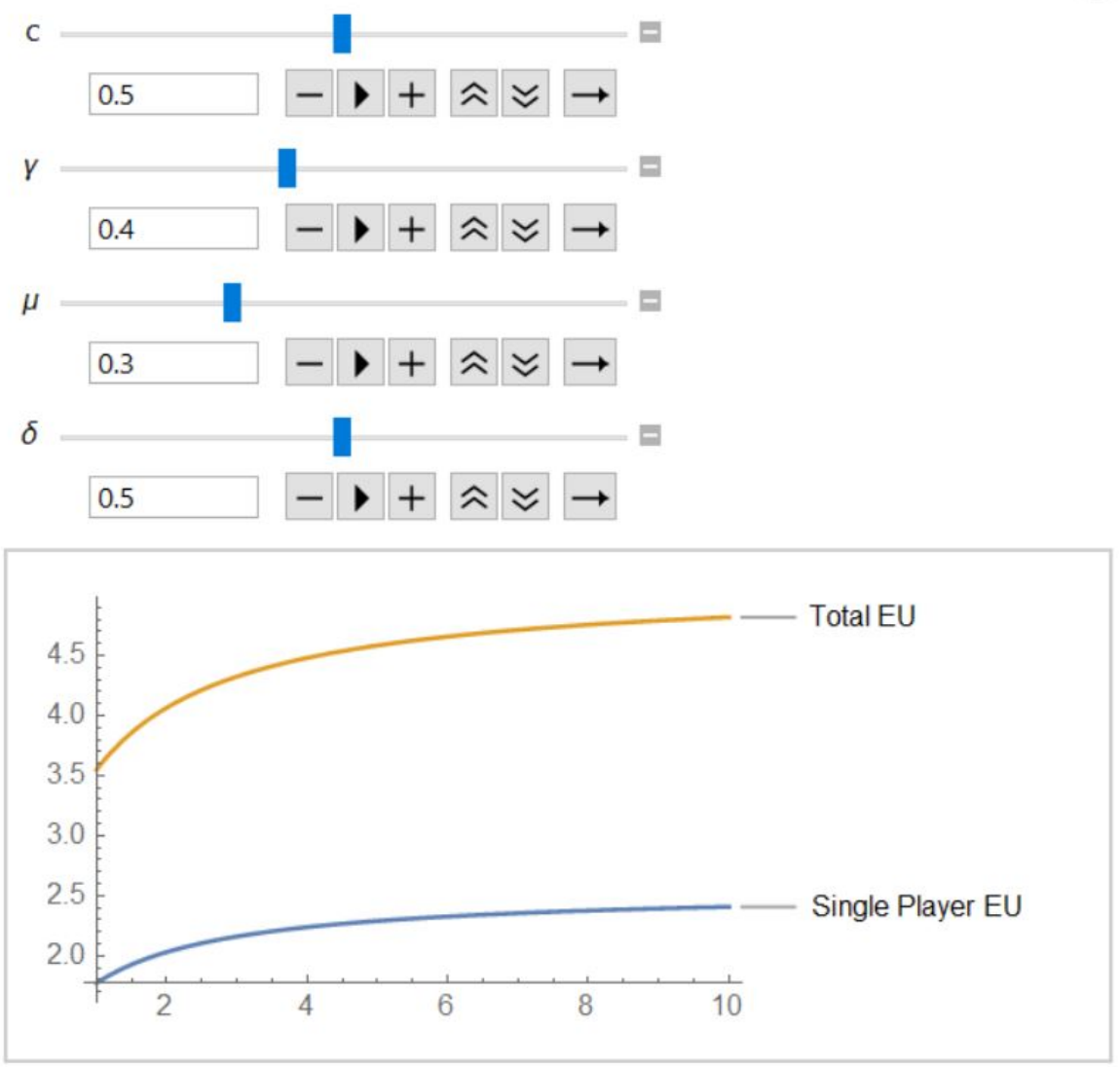


\section{Comparative statics}

Importantly, because we now have a reduced-form solution for total welfare (i.e. total expected utility) in figure A5, we can do comparative statics to see how welfare in the attack-defend dyad changes with the offense-defense balance:

$$
\frac{\partial E U_{t o t a l}}{\partial m}=\frac{\phi}{(1+m)^{2}}
$$

This figure is strictly positive as $m>0$ and $\phi>0$ by assumption, so therefore total EU is strictly increasing in offensive advantage for the simultaneous attack war equilibrium.

Under partial arming, equilibrium arms levels are decreasing when $m>1$. This drives higher welfare under offensive advantage, since players choose to spend less on arms as offensive advantage increases.

$$
\frac{\partial a}{\partial m}=\phi\left(1-m^{2}\right)
$$

\section{Solving the Dynamic Model with Endogenous Arming and Endogenous War Costs}

Let's start with the decision to arm discussed in section 11 Recall that the Lagrangian for that decision problem was:

$$
\left.L=1-a+p^{i}(a, \hat{a} ; m)\right) \phi+\lambda a+\theta(1-a)
$$

Where $\phi=\frac{[\gamma-c+\delta(1+\mu)]}{(1-\delta)}$, i.e. the perpetuity benefit from winning the war. The only difference in our setup now is that $\phi$ is now longer completely exogenous, as $\mathrm{c}$ is now a function of $\pi_{s}$, which is a function of arms levels.

Now the decision problem becomes:

$$
\max _{a} 1-a+p^{i}(a, \hat{a} ; m) \frac{[\gamma+\delta(1+\mu)]}{(1-\delta)}-p^{i}(a, \hat{a} ; m) \frac{k}{\left(1-\pi_{s}(m)\right)(1-\delta)}
$$

Let's start by just considering the internal solution where $a \in(0,1)$. Recall that the attacker will choose arms levels such that the marginal benefit of arms equals the marginal cost of arms. When $\phi$ was completely exogenous, then this condition was:

$$
\frac{\partial p^{i}(a, \hat{a} ; m)}{\partial a} \phi=1
$$

Now that $\phi$ is partially endogenous, we have to split it up into its component parts, 
and the condition becomes:

$$
\frac{\partial p^{i}(a, \hat{a} ; m)}{\partial a} \frac{[\gamma+\delta(1+\mu)]}{(1-\delta)}-\frac{\partial p^{i}(a, \hat{a} ; m)}{\partial a} \frac{k}{\left(1-\pi_{s}(m)\right)(1-\delta)}=1
$$

This new condition still equates marginal benefit to marginal cost, but the attacker also needs to consider the effect that their arming will have on the cost of war. To simplify the notation, we will specify $\theta$ as the perpetuity benefit of winning the war that excludes the war cost:

$$
\theta=\frac{[\gamma+\delta(1+\mu)]}{(1-\delta)}
$$

From here, we can use the same steps as the previous section to solve the model. We use the above condition to solve for optimal arms levels for the attacker as a function of the defender's arms levels. Then we do the same analysis from the persepective of the defender. Then we can solve for the Nash Equilibrium arms levels as a function of exogenous variables shown in the figures below.

FIGURE A7

\section{Nash Equilibrium Reduced Form Arms Levels and Expected Utility under Simultaneous Attack Dyad}

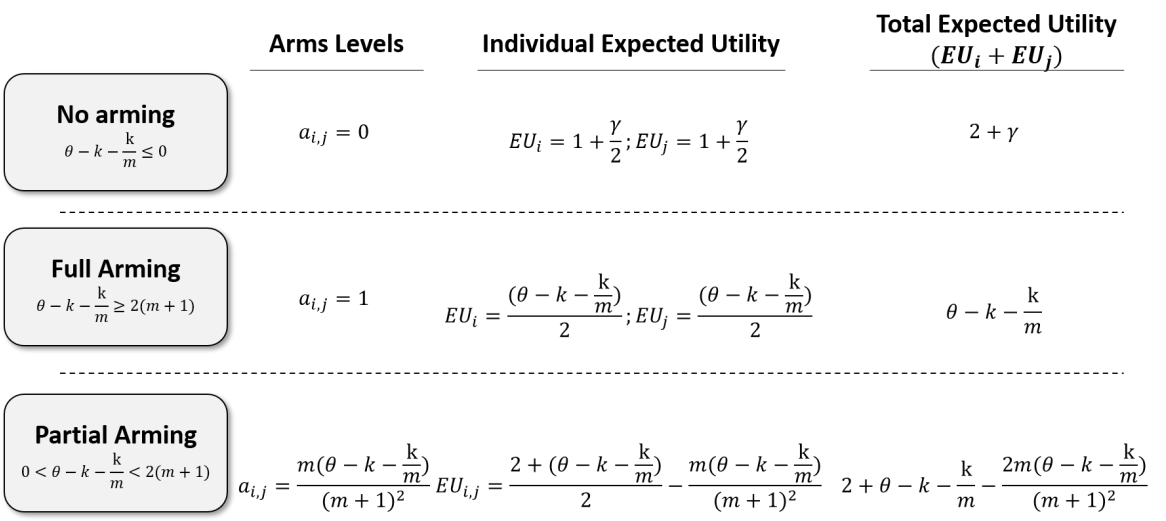




\section{Nash Equilibrium Reduced Form Arms Levels and Expected Utility under Attack-Defend Dyad}

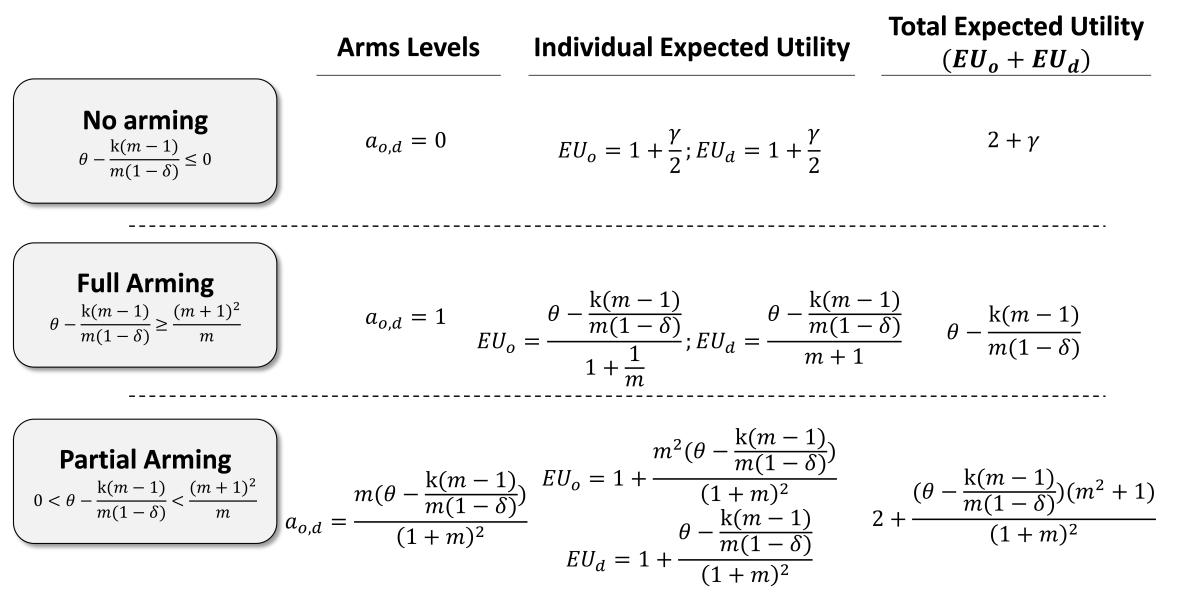

We see a similar WUO curve to the one shown in section 11 except a much more pronounced increase of welfare under offensive advantage, including in situations where $\delta \rightarrow 1$ because the cost of war is now decreasing in offensive advantage.

\section{Proofs of Propositions}

Proposition 1: In the one-shot model with exogenous arms levels and with sufficiently low war cost (c) such that that the Pyrrhic Victory condition does not hold, for sufficient defensive advantage (sufficiently low $m$ ), peace is the only equilibrium outcome; for sufficient offensive advantage (sufficiently high $\mathrm{m}$ ), war is the only equilibrium.

Proof: Start with the first part of the proposition. Assume that defense is advantaged $(m<1)$, so therefore the game structure is either "Rope-A-Dope" with two anti-coordination war pure strategy Nash equilibria or "Stable Deterrence" with a single peace equilibrium as shown in figure 2. For the game structure to be "Rope-A-Dope," the static war constraint (equation 1) must not hold, and therefore:

$$
\frac{1-a+\gamma / 2}{(1-\delta)}<1-a+p_{o}(m) \frac{w}{(1-\delta)}
$$


However, assume that $m$ is very small such that $m \rightarrow 0$. Therefore, $p_{o}(m) \rightarrow 0$ by condition 6 that we specified for the war contest success function previously. Therefore, the expected payoff from war is $1-a$, and therefore the static war constraint will not hold. This implies that the game is "Stable Deterrence," and that there is a single peace equilibrium.

Now we address the second part of the proposition. Assume that offense is advantaged $(m>1)$, so therefore the game structure is either "Security Dilemma" with a peaceful pure strategy Nash equilibrium and a simultaneous attack war pure strategy Nash equilibria, or "Offensive War" with a single simultaneous attack Nash equilibrium. For the game structure to be "Security Dilemma," the static war constraint (equation 1) must hold, and therefore:

$$
\frac{1-a+\gamma / 2}{(1-\delta)} \geq 1-a+p_{o}(m) \frac{w}{(1-\delta)}
$$

However, assume that $m$ is very large such that $m \rightarrow \infty$. By condition 6 that we specified for the contest success function previously, therefore $p_{o}(m) \rightarrow 1$, which implies that the attacker will win with $100 \%$ certainty. However, if the war constraint were to hold, this would imply that peace is preferred to a predatory attack that succeeds with $100 \%$ certainty, which would imply that the Pyrrhic victory condition would hold by definition. However, the proposition assumes that the Pyrrhic victory condition does not hold, so this is a contradiction. Therefore, the static war constraint does not hold, which implies that the game structure is "Offensive War," and the only Nash equilibrium outcome is simultaneous attack and war. QED.

Proposition 2: In the dynamic model with endogenous arming and exogenous war costs that are sufficiently low such that that the Pyrrhic Victory condition does not hold, when players are perfectly patient $(\delta \rightarrow 1)$, state welfare is weakly decreasing under higher offensive advantage (higher $m$ ).

Proof

For sufficient defensive advantage (sufficiently small $m$ ), peace is an equilibrium. Welfare is decreasing under higher offensive advantage (higher $m$ ) in Pareto optimal peace equilibria as higher arms burdens are required to maintain deterrence. We prove this in the more general case for proposition 3 below.

For sufficient offensive advantage (sufficiently high $m$ ), war is an equilibrium because states cannot spend enough on arms to deter an opponent from engaging in a predatory attack. We also prove this in the more general case for proposition 3 below.

War equilibria result in full arming $(\mathrm{a}=1)$, and state welfare is unchanged under offensive advantage in the war equilibrium. This follows from Fearon 2018 footnote 26 and the proof to his proposition 2 show that states will fully arm in war equilibria when $\delta=1$. Futhermore, all of the other variables that affect payoffs are given exogenously, so if states fully arm in war equilibria for all values of $m$, then state welfare (the net present value of state payoffs) will remain constant in 
war equilibria. QED.

Proposition 3: In the dynamic model with endogenous arming and exogenous war costs that are sufficiently low such that the Pyrrhic Victory Condition does not hold, and where players place sufficient value on the present period relative to future periods ( $\delta$ is sufficiently small) such that there is partial arming in equilibrium $a \in(0,1)$, state welfare is $u$-shaped under offensive advantage (WUO) in equilibrium.

\section{Proof}

For sufficient defensive advantage (sufficiently small $\mathrm{m}$ ), peace is an equilibrium. In proposition 2 in Fearon 2018, Fearon proved that the $\mathrm{a}^{*}$ that solves the war constraint with equality is the most cooperative peaceful equilibrium, and definitely exists provided that $a^{*}<a^{N E}$. As discussed in the main text, we also assume that $a^{*}<a^{N E}$, and thus this result holds in our model as well. See the Fearon 2018 supplementary materials for the full proof of that result.

Welfare is decreasing under higher offensive advantage (higher $m$ ) in Pareto optimal peace equilibria. Fearon 2018 shows this in proposition 3. In his proof given in his supplementary materials, Fearon showed that $\frac{\partial a^{*}(m)}{\partial m}>0$, which is because higher arms levels are required to mantain deterrence under higher levels of offensive advantage.

For sufficient offensive advantage (sufficiently high $m$ ), war is an equilibrium because states cannot spend enough on arms to deter an opponent from engaging in a predatory attack. We show this by assuming that offense is extremely advantaged such that $m \rightarrow \infty$. In order for a peace equilibrium to be supported, the dynamic war constraint, equation (3), must hold:

$$
\frac{1-\hat{a}+\gamma / 2}{(1-\delta)} \geq \max _{a} 1-a+p_{o}(a, \hat{a} ; m) \frac{\gamma-c+\delta(1+\mu)}{(1-\delta)}
$$

By condition 6 that we specified for the contest success function previously $p_{o}(m) \rightarrow 1$, which implies that the attacker will win with $100 \%$ certainty provided that the attacker spends some $a>0$ on arms. Assume that the attacker spends some small $\epsilon>0$ on arms such that they can win the war with $100 \%$ certainty at negligible arms spending. Now, equation (3) becomes:

$$
\frac{1-\hat{a}+\gamma / 2}{(1-\delta)} \geq 1+\frac{\gamma-c+\delta(1+\mu)}{(1-\delta)}
$$

However, the proposition specifies that the Pyhrric victory condition does not hold. From the equation preceding equation (4) in the main text, this implies that: 89

89. We assume here for convenience that when the two sides of the Pyhrric victory condition are equal, the tie goes to the Pyrrhic victory condition holding, although this distinction is semantic. 


$$
\frac{1+\gamma / 2}{1-\delta}<1+\frac{\gamma-c+\delta(1+\mu)}{1-\delta}
$$

However, this implies that equation $\mathrm{A55}$ cannot hold because $a \in[0,1]$. This is a contradiction, and therefore the war constraint does not hold, and war is the only equilibrium outcome.

In war equilibria with partial arming, welfare continues to decrease in offensive advantage when defense remains advantaged ( $m<1$, which implies the rope-adope scenario). This follows directly from equation (A40, which was derived above using the KKT conditions for the case when $m<1$. However, welfare increases in offensive advantage in the war equilibria when offense becomes advantaged ( $m>1$, which implies the offensive war scenario). This follows directly from equation (A52, which was derived above using the KKT conditions for the case when $m>1$. When $m<1$, war equilibria with partial arming occur when $\frac{[\gamma-c+\delta(1+\mu)]}{(1-\delta)}<\frac{(m+1)^{2}}{m}$. This follows directly from equation A20, which was derived above using the KKT conditions for the case when $m<1$. When $m>1$, war equilibria with partial arming occur when $\frac{[\gamma-c+\delta(1+\mu)]}{(1-\delta)}<2(m+1)$. This follows directly from equation $\mathrm{A} 50$, which was derived above using the KKT conditions for the case when $m>1$.

Even though the war remains decisive in the model (one side is eliminated in perpetuity), higher offensive advantage causes wars to be less total in equilibrium when $m>1$ (a lower fraction of state resources are spent on arms levels), which increases state welfare. This follows directly from equation (A53), which was derived above using the KKT conditions for the case when $m>1$. This shows that in equilibrium, players spend a smaller fraction of their resources on arms under higher offensive advantage when $m>1$. QED.

Proposition 4: In the dynamic model with endogenous arming and endogenous war costs, welfare is u-shaped under offensive advantage-decreasing in peace equilibria and increasing in war equilibria for sufficiently high offensive advantage - under all patience and arming scenarios provided that the cost of military operations is sufficiently low such that the Pyrrhic Victory Condition does not hold.

\section{Proof:}

Proposition 2 established that welfare is decreasing under offensive advantage in peace equilibria, and this continues to hold as higher arms levels are required to deter attacks that are more likely to be successful under higher levels of offensive advantage. Proposition 3 established that welfare increases under war equilibria when $m>1$ under partial arming scenarios (which only occur when $\delta<1$ ) due to diminishing marginal returns from arming under higher offensive advantage. Therefore, the WUO result held in the dynamic model with exogenous war costs, but the increasing portion of the WUO curve that results from higher welfare in war equilibria only held in partial arming equilibria. 
The model with endogenous war costs introduces a new mechanism by which the offense defense balance effects welfare: by affecting the cost of war through the operational model of war described in the main text.

The mechanism by which higher offensive advantage increases welfare by reducing equilibrium arms spending in war scenarios with partial arming continues to hold, but the new mechanism introduced in this iteration of the model is the operational model of war, which produces the result that higher offensive advantage causes war to be less costly in expectation. Thus, this new mechanism works towards increasing state welfare in war equilibria even when states fully arm. We will restrict our proof here to show that state welfare continues to increase in war scenarios even when states fully arm, which causes the WUO result to hold even when states are perfectly patient $(\delta \rightarrow 1)$ and war equilibria involve full arming. In figure A7, we show the equilibrium level of arms and welfare in the simultaneous attack war that was solved for by applying the KKT conditions. From this figure, the reduced form solution for total welfare when states are fully arming is:

$$
E U_{\text {total }}(\text { Simultaneous Attack })=\frac{[\gamma+\delta(1+\mu)]}{(1-\delta)}-k-\frac{k}{m}
$$

And from this figure, we can see that total welfare is increasing in offensive advantage because $\mathrm{k}$ and $\mathrm{m}$ are positive:

$$
\frac{\partial E U_{\text {total }}(\text { SimultaneousAttack })}{\partial m}=\frac{k}{m^{2}}
$$

Thus even in scenarios when states are perfectly patient $(\delta \rightarrow 1)$ and thus fully arm, welfare will continue to improve under offensive advantage in the war scenario when $m>1$. QED.

Proposition 5: Provided that the cost of military operations is sufficiently small such that the Pyrrhic victor condition does not hold, non-marginal shocks to the offense-defense balance in favor of attackers can cause an absolute increase in state welfare by switching from a costly peace equilibrium burdened by high arms levels to maintain deterrence to a decisive war equilibrium.

\section{Proof:}

For simplicity, consider the dynamic model with exogenous war costs. Assume that the parameter values are such that a peace equilibrium can be supported because the war constraint holds, and assume that the peace equilibrium is the Pareto optimal peace equilibrium that involves arms levels $\mathrm{a}^{*}$ that solve the war constraint with equality. Thus total welfare for the players is:

$$
\frac{2-2 a^{*}+\gamma}{(1-\delta)}
$$

Now assume that there is a shock to military technology such that offense becomes 
advantaged enough such that the war constraint can no longer hold (and that $m>1$ ). By equation (A47), total welfare for the players is:

$$
\frac{2+\frac{w}{(1-\delta)}}{2}-\frac{m \frac{w}{(1-\delta)}}{(m+1)^{2}}
$$

In order for the war to be total welfare improving over peace, it must be the case that:

$$
\frac{2-2 a^{*}+\gamma}{(1-\delta)}<\frac{2+\frac{w}{(1-\delta)}}{2}-\frac{m \frac{w}{(1-\delta)}}{(m+1)^{2}}
$$

This simplifies to:

$$
1+\gamma+\delta+w\left[\frac{m}{(m+1)^{2}}-\frac{1}{2}\right]<2 a^{*}
$$

Now assume that the shock was significant so that $m \rightarrow \infty$. Note that $\lim _{m \rightarrow \infty} \frac{m}{(m+1)^{2}}=0$. Therefore, the previous inequality further simplifies to:

$$
1+\gamma+\delta-2 a^{*}<\frac{1}{2} w
$$

We can see for reasonable parameter values that this inequality holds. For instance, assume $\gamma=0.5, \delta=0.9, c=0.5$, and $\mu=0.5$. If we plug in these values to this inequality, we get that:

$$
-2 a^{*}<4.35
$$

Which clearly holds because $a \in[0,1]$, and a deterrence equilibrium definitely exists provided that $\mathrm{m}$ is sufficiently low, as proved earlier. QED.

Dummy dates; Date received: MMMM DD, YYYY; Date accepted: MMMM DD, YYYY. please ignore. 